\title{
Caring for Yourself While Caring for Others
}

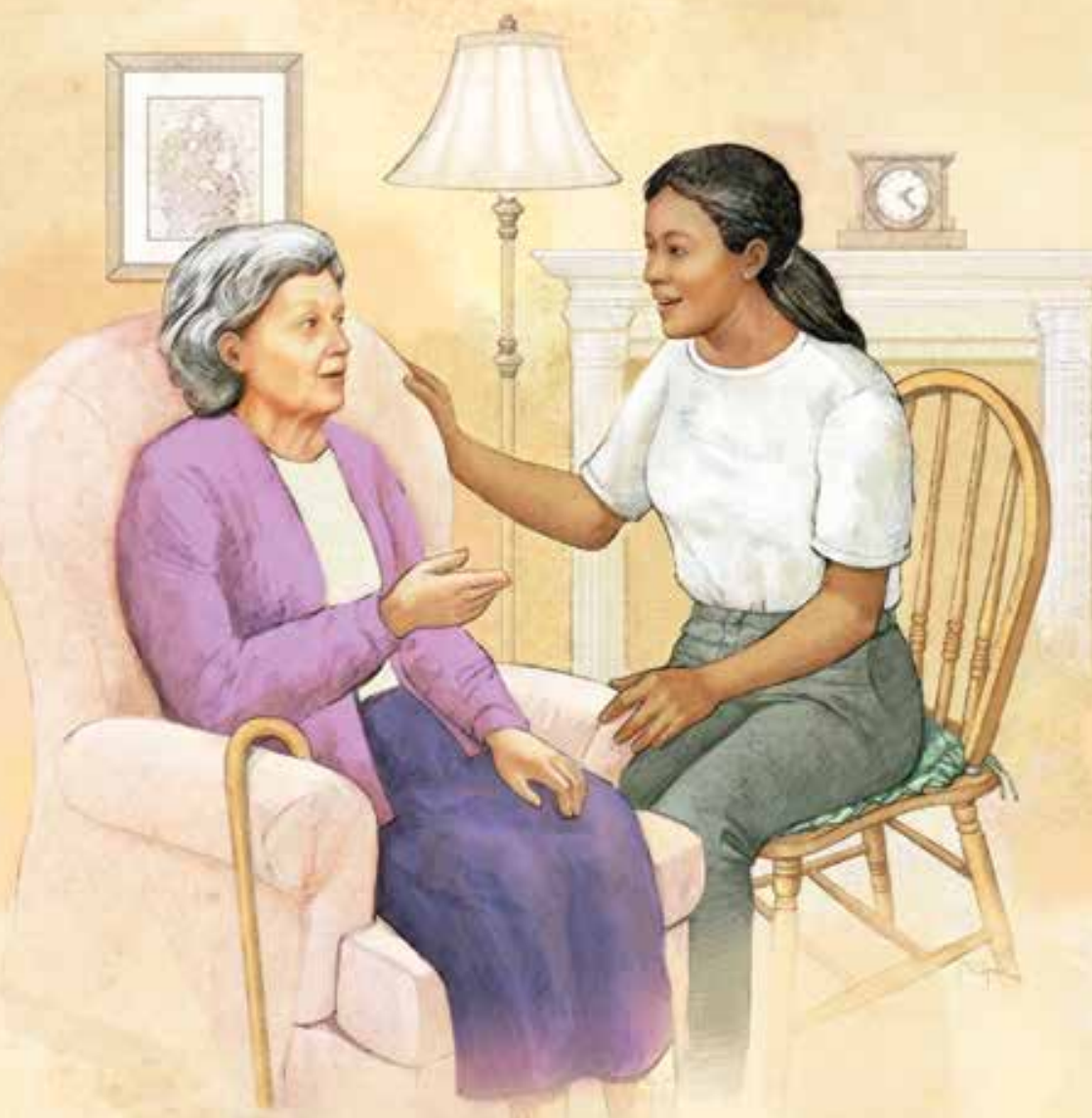

Practical Tips for Homecare Workers

STAY SAFE AT WORK 
This document is in the public domain and may be freely copied or reprinted.

\section{Disclaimer}

Mention of any company or product does not constitute endorsement by the National Institute for Occupational Safety and Health (NIOSH). In addition, citations to websites external to NIOSH do not constitute $\mathrm{NIOSH}$ endorsement of the sponsoring organizations or their programs or products. Furthermore, NIOSH is not responsible for the content of these websites. All Web addresses referenced in this document were accessible as of the publication date.

\section{Ordering Information}

To receive documents or other information about occupational safety and health topics, contact $\mathrm{NIOSH}$ :

Telephone: 1-800-CDC-INFO (1-800-232-4636)

TTY: 1-888-232-6348

CDC-INFO: www.cdc.gov/info

or visit the NIOSH website at www.cdc.gov/niosh.

For a monthly update on news at NIOSH, subscribe to NIOSH eNews by visiting www.cdc.gov/niosh/eNews.

\section{Suggested Citation}

NIOSH [2014]. Caring for yourself while caring for others. Cincinnati, OH: U.S. Department of Health and Human Services, Centers for Disease Control and Prevention, National Institute for Occupational Safety and Health, DHHS (NIOSH) Publication No. 2015-103.

DHHS (NIOSH) Publication No. 2015-103

\section{November 2014}

SAFER • HEALTHIER • PEOPLE ${ }^{\text {TM }}$ 


\section{Caring for Yourself While Caring for Others}

\section{Practical Tips for} Homecare Workers
STAY SAFE AT WORK 


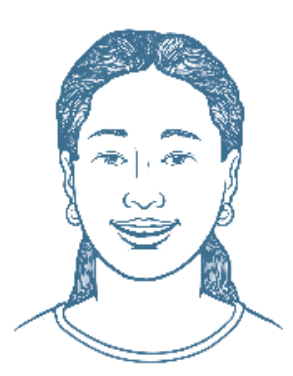

\section{Hello!}

My name is Natalia.

I love being a homecare worker! But it can be dangerous. Two

years ago, I slipped while helping Clara take a shower.

I twisted my ankle and was on crutches for two weeks. I couldn't work, so I didn't get paid, and I couldn't take care of my family and the people who needed me.

That changed the way I look at my job. I found there's a lot to learn, and what we don't know CAN hurt us -and the people we care for.

\section{We can protect ourselves.}

Before I got hurt, I didn't think much about my own safety. Now, I think things through before doing them. I watch out for hazards and try to use the right tools and techniques. This handbook helps me do my work well and safely.

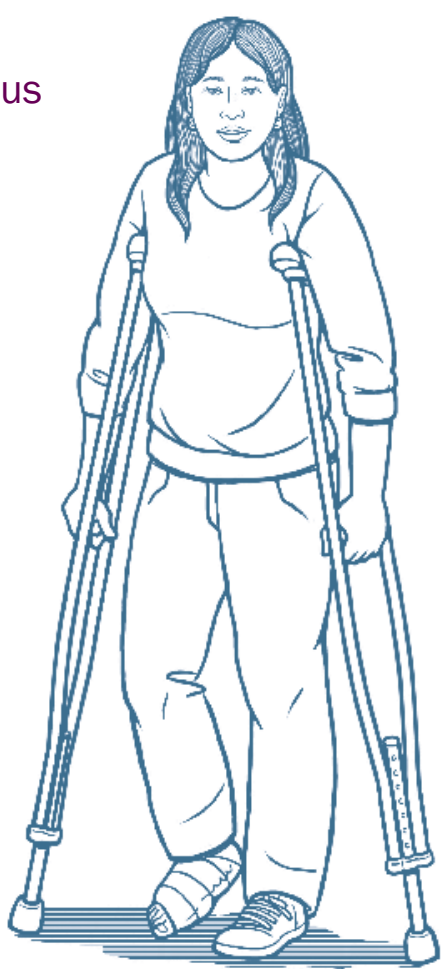




\section{I'm Clara.}

Natalia has worked for me for 3 years. When she got hurt, it really shook me up. As her employer, I'm responsible for making my home a safe workplace. I don't ever want anyone to get hurt again while helping me.

I care about her. And, if she gets hurt, my life gets much harderI have to show another worker how to take care of me.

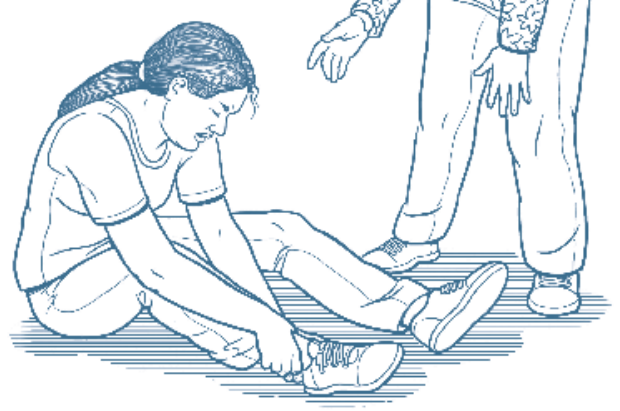

\section{Why should clients read this handbook?}

I've heard lots of things about safety, but it's hard to find one source of reliable information. That's what this handbook is: a collection of

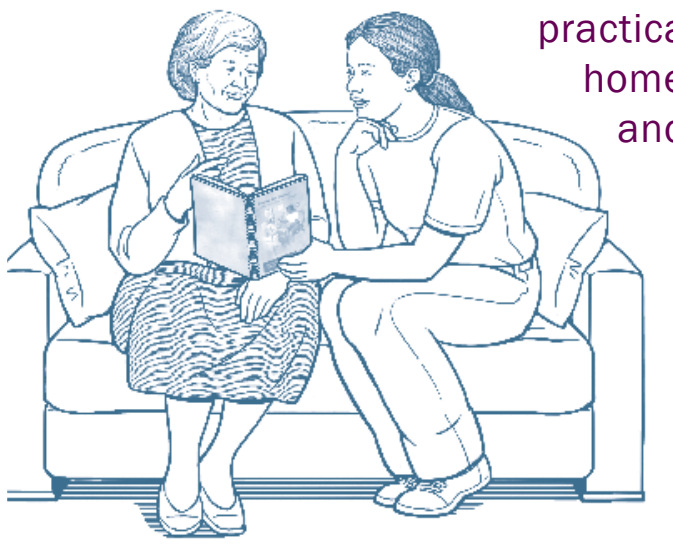

\section{Turn the page to learn how to use this handbook}




\section{How to use \\ this handbook}

1. Look over the checklist on the next page and see which safety tips apply to you. Go to those pages to find out

What to watch out for, and the $\checkmark$ tools and tips that can help you both stay safe.

2. Read "How to talk to each other about safety" on page 6 for suggestions on how to communicate your concerns to each other. Each safety tip also has a

talk it over section with examples of what you could say.

Working with the client is the best way, but it is not the only way to use the handbool.

You can use it on your own or with others such as family members or guardians.

If you work for an agency you can also ask your supervisor for information or help. 
3. Keep track of good ideas to make your work safer. Fill out the to do list at the end of each safety tip:

\section{to do list}

Supplies needed:

$\square$ Long-handled duster, mop, scrub brush

$\checkmark$ Stepstool $\square$ kneepads $\square$ Other: Cleaning gloves New ways to do the tasks:

Tie a rag to end of a broom to dust upper shelves

People or places we will contact for help, tools, or information:

Consumer will ask her family if they have kneepads

Worker will mix dish soap and water (p.19) for trying out the general cleaner.

4. Create your own action plan for safety on page 72 . Keep it on hand to remind you both about staying safe.

5. 2 Review the find help section at the end of each safety tip. If you work for an agency, check with your supervisor to see what resources and support might be available.

Remember, staying safe on the job is important not only for you, but also the people you care for. Congratulations on taking time to Care for Yourself While Caring for Others. 


\section{Checklist}

\section{What hazards \\ are you exposed to?}

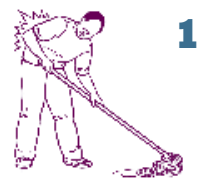

1. Do you mop, scrub, or do other housecleaning tasks for the client?

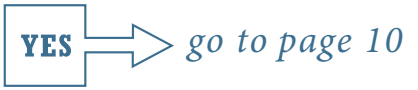

2. Do you use cleaning products such as bleach or toilet cleaner?

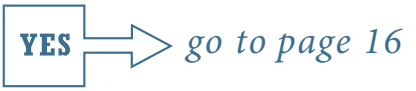

3. Do you do the client's laundry?

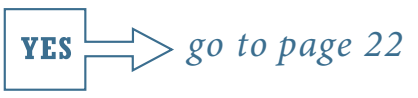

4. Do you help the client move (transfer) from place to place in the home?

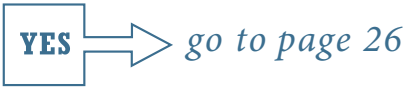

5. Do you help the client take a bath or shower?
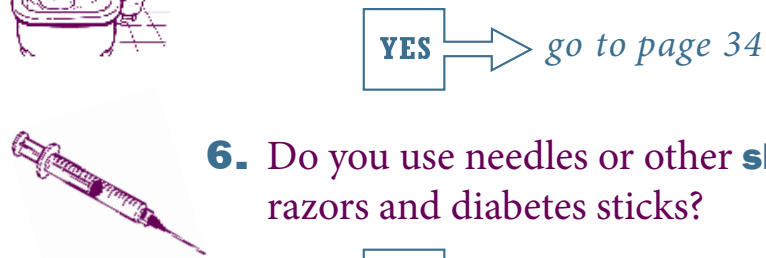

6. Do you use needles or other sharp objects such as razors and diabetes sticks?

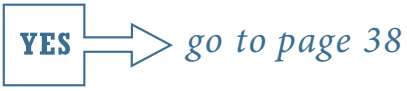


7. Do you cook and shop for the client?
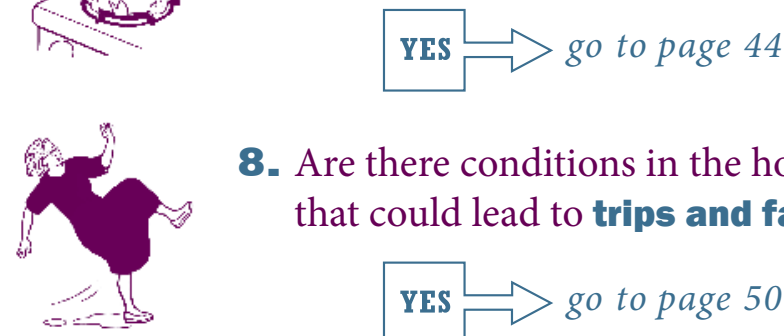

8. Are there conditions in the home that could lead to trips and falls?
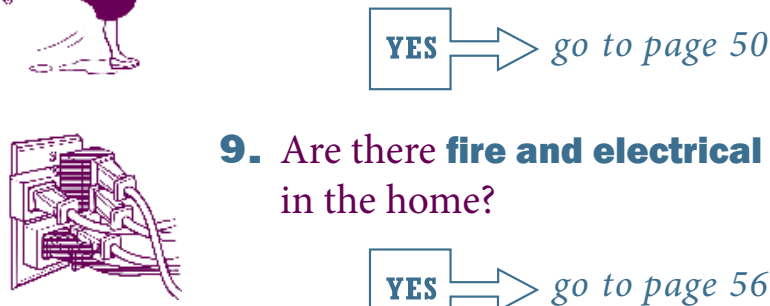

9. Are there fire and electrical hazards in the home?
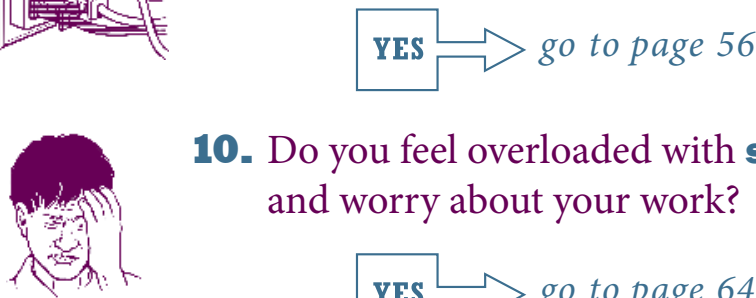

10. Do you feel overloaded with stress and worry about your work?
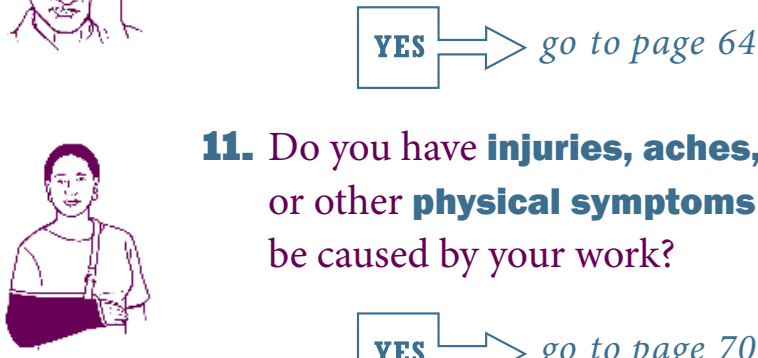

11. Do you have injuries, aches, and pains or other physical symptoms that might be caused by your work?

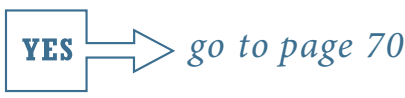

Create your own action plan for safety

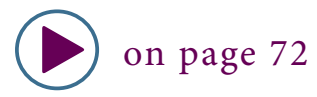

\section{Let's get started!}

Turn the page for tips on how to talk to each other about safety. 


\section{How to talk to each other about safety}

\section{What's wrong with this conversation?}

“You can't keep your

stuff all over the place.

It's too cluttered-and

dangerous!"

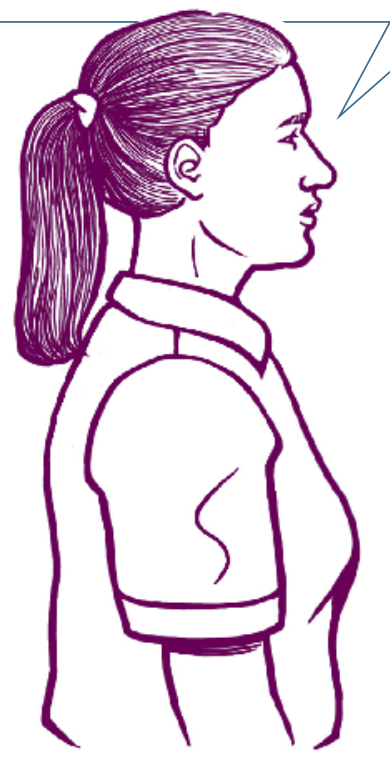

“It's MY house! You can't tell me what to do!"
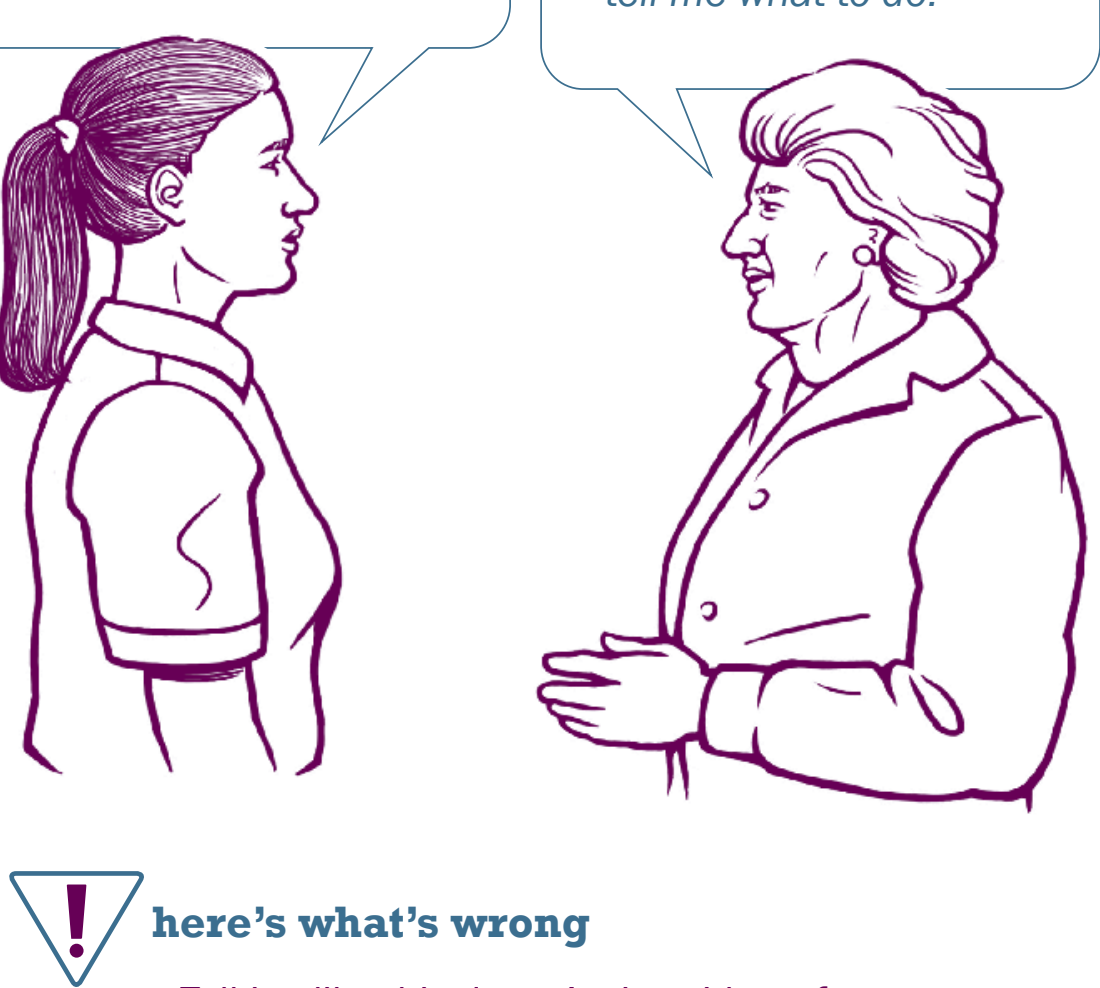

here's what's wrong

- Talking like this doesn't give either of you room to think of solutions.

- Each person may feel the other is not respectful and doesn't care about her or his needs. Both of you can get angry and defensive. 


\section{tips for effective communication}

Learn ways to state a concern about your safety in a manner that encourages both of you to find a positive solution-together.

\section{- Bring up a safety issue as soon as possible.} If you don't, the problem can get worse, and one or both of you can get hurt.

- Plan the discussion. Practice with a friend or write down what you want to say.

\section{- Be respectful.}

Homecare worker: "May I move the phone cord out of the way so we don't trip? I'll make sure you can still reach the phone easily."

- Use "I" statements. Talk about what you observe and how it affects you rather than blame the other.

Homecare worker: "If I tried that, I'm afraid that I could hurt my back."

Client: "I worry that if we change the way things are organized I won't be able to find the things I need."

\section{Look at the issue from the other person's} perspective.

Homecare worker: "It must be hard having someone rearrange your things. But I wonder if we can move some things from the floor so we'd have more room to walk."

Client: "I've always done the laundry that way, but if it puts too much strain on your back, it's OK with me to try it another way." 
tips for effective communication continued

Consider several solutions so there's not just one option.

Homecare worker: "That cleaning product is too strong for me. I'm concerned about my health. I could continue using it if I can open the window or use a fan. Or I could make a cleaner that works as well but is safer and less expensive. Which would you prefer?

- Know your bottom line-the least that you can accept while still protecting the health and safety of yourself or your client.

Homecare worker: "I'm sorry. I'm not comfortable changing the bandage without wearing gloves. Using gloves is safer for both of us."

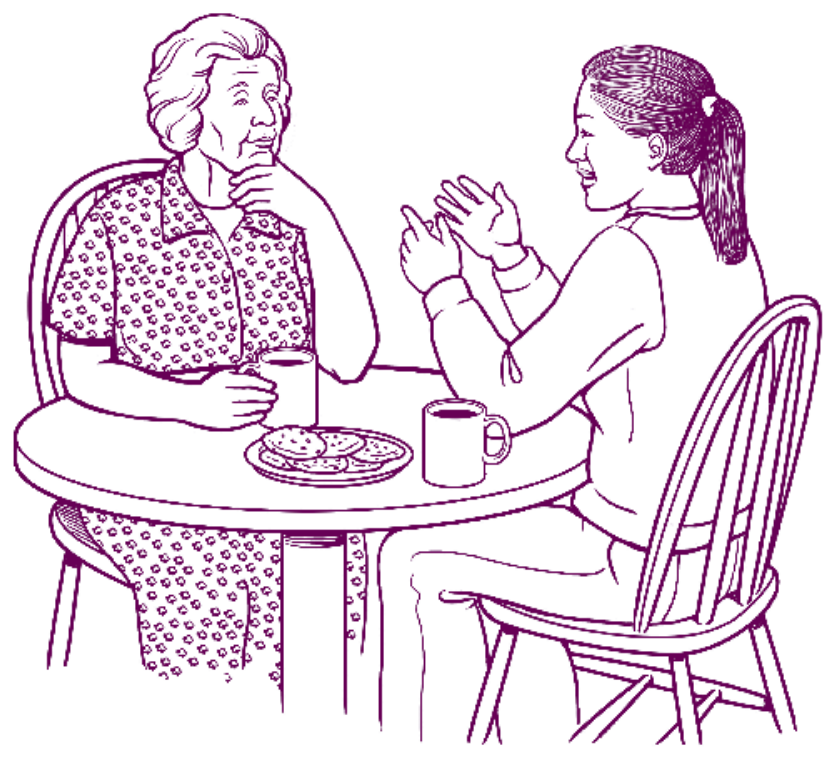




\section{tips for working with clients}

who have speech difficulties

- Find a quiet area and give them your full attention.

- Don't interrupt or finish their sentences.

- If you have trouble understanding, don't nod. Simply ask them to repeat.

- If after trying, you still cannot understand them, ask them to write it down or suggest other ways, such as these:

- Communication boards and books.

- Computers (text or graphics/pictures).

- Help from a family member or friend who is experienced in communicating with the client.

\section{when communication breaks down}

Sometimes you may feel threatened by what clients or other people in the house say or do. If you believe you are in immediate danger, call 911.

Otherwise, consider these options:

- Talk to the client when he or she is calm.

- If you work for an agency, ask for help from your supervisor.

- Ask a friend or family member to go with you when you speak with the client.

- If you can't resolve the situation, consider other employment for yourself or other care options for the client. 


\section{Mopping, scrubbing, and other housecleaning tasks}

\section{don't}

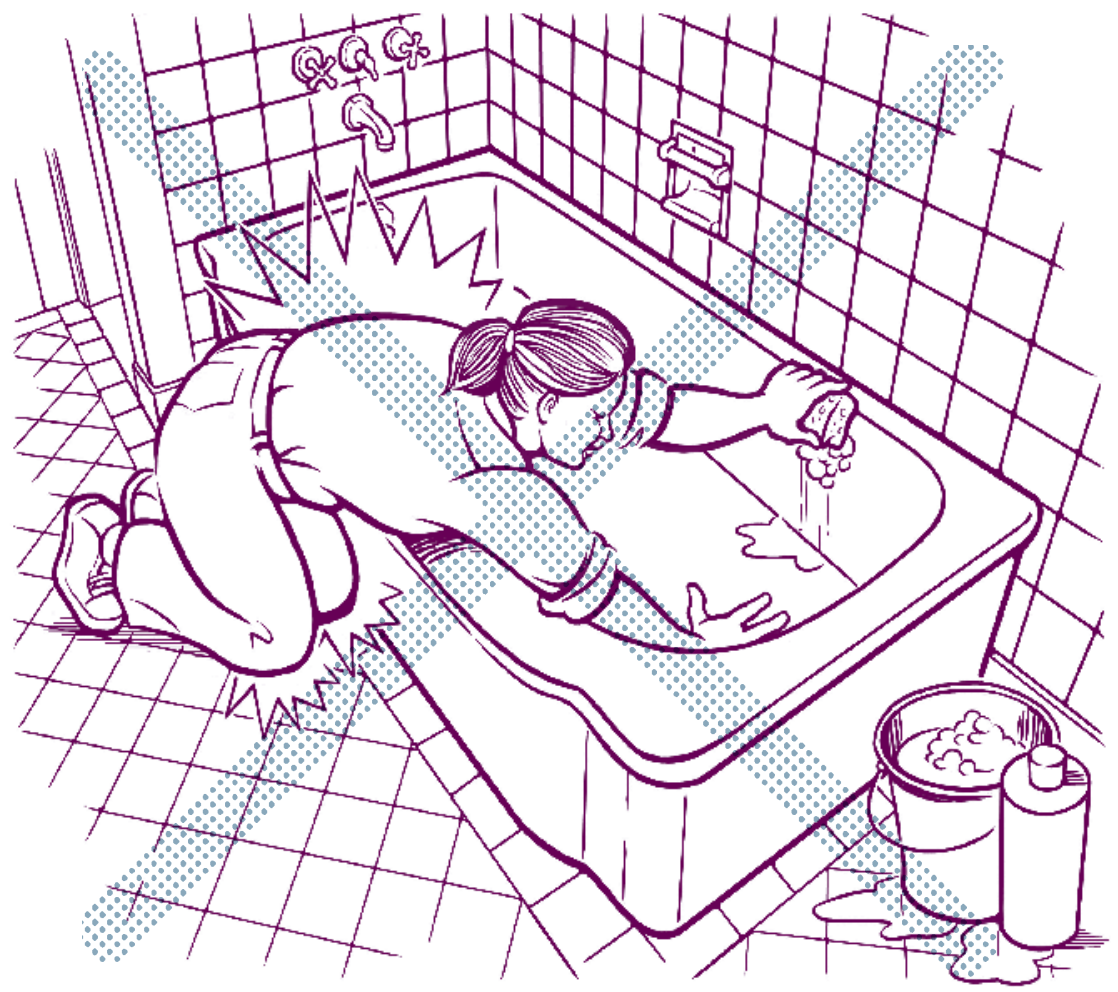

\section{! watch out for}

Back and shoulder injuries - General aches and pains 


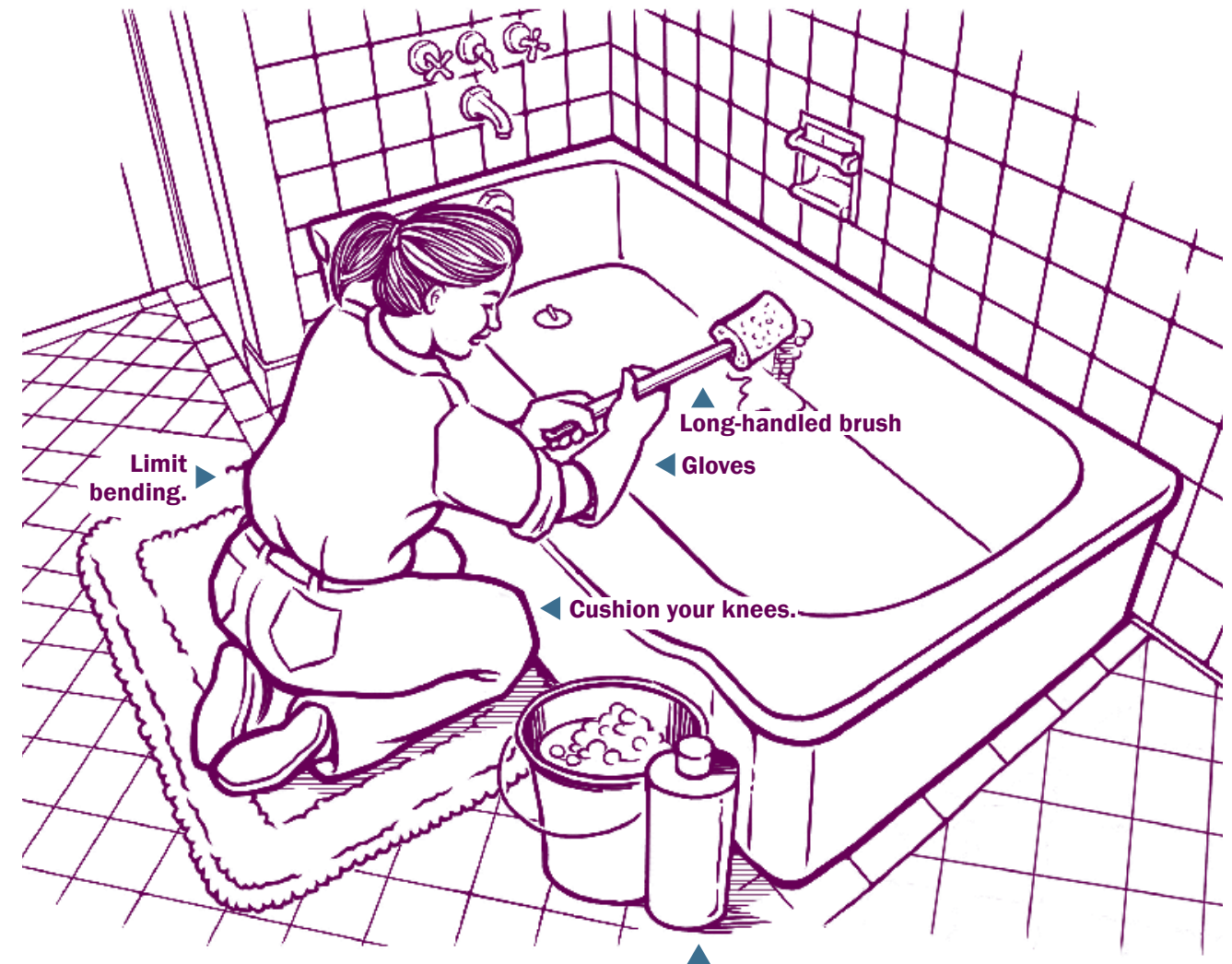

Keep supplies near.

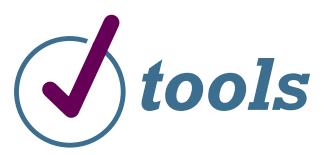

Use these things to make the tasks safer:

- A long-handled duster, mop, and scrub brush to limit bending while you clean the floor, walls, tubs, and toilets.

- A stepstool to help you clean high places without overreaching and possibly losing your balance.

- Knee pads or a folded towel to cushion your knees. 


\section{tips}

- Avoid reaching and bending. Move as close as possible to the task. For example, when making a bed, walk around it so you don't have to reach. Raise the bed if it is adjustable.

- Every few minutes, stretch and change positions. Switch hands if you can.

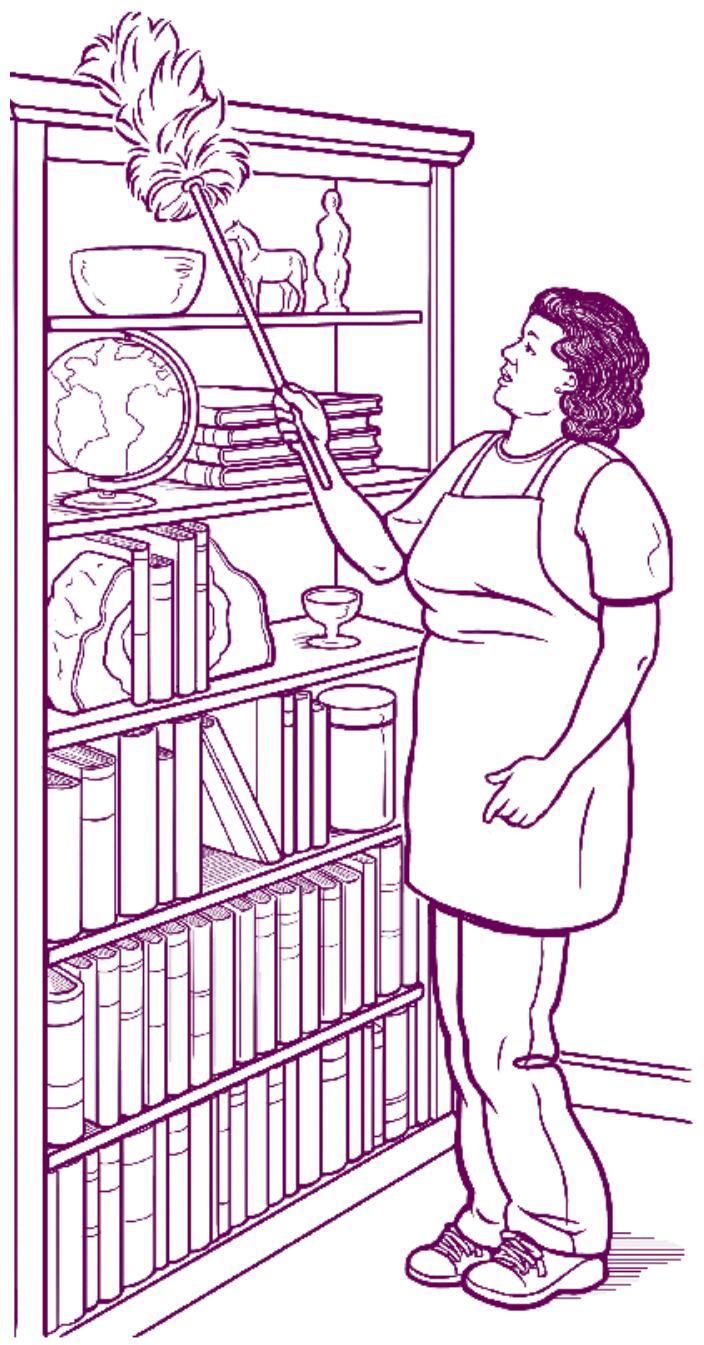

“Sometimes l've attached a rag to the end of a broom to clean hard-toreach places." 
- Try not to twist your body-move your feet instead. Bend your knees, not your back.

- When lifting a heavy object, hold it close to your body. Lift with your legs. This puts less stress on your back. If it's too heavy to lift without strain, get help.

- If you move furniture to clean the floor, push, don't pull. If it's too hard to move, get help. Put casters on the feet of heavy furniture so it is easier to move.

"If there is anything heavy that needs to be lifted, I won't let the homecare worker lift it alone. We either ask for help from a neighbor or my nephew, or we slide things, or put them in a cart and push it."

Dennis, client 


\section{talk it over}

You could say this: "Tools with long handles make it easier on my back and help me stay strong and healthy enough to keep working."

\section{? find help}

\section{Hardware and discount stores}

sell stepstools, long-handled tools, kneepads, and casters and sliders for furniture.

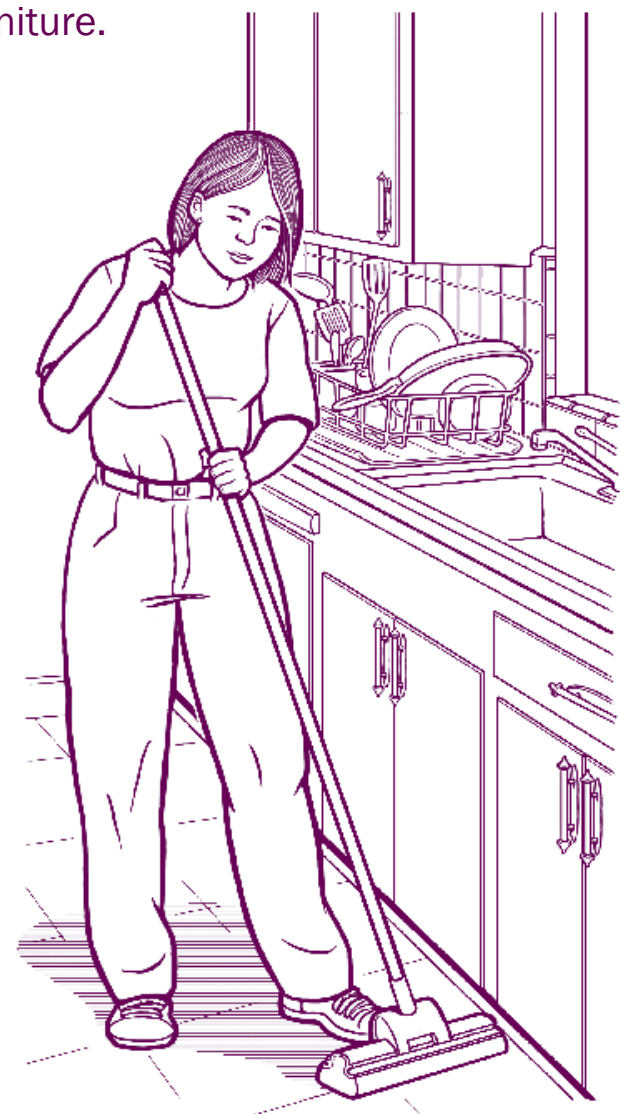




\section{to do list}

Supplies needed:

$\square$ Long-handled duster, mop, scrub brush

$\square$ Stepstool $\quad \square$ Kneepads $\quad \square$ Other:

New ways to do the tasks:

People or places we will contact for help, tools, or information: 


\section{Working with cleaning products}

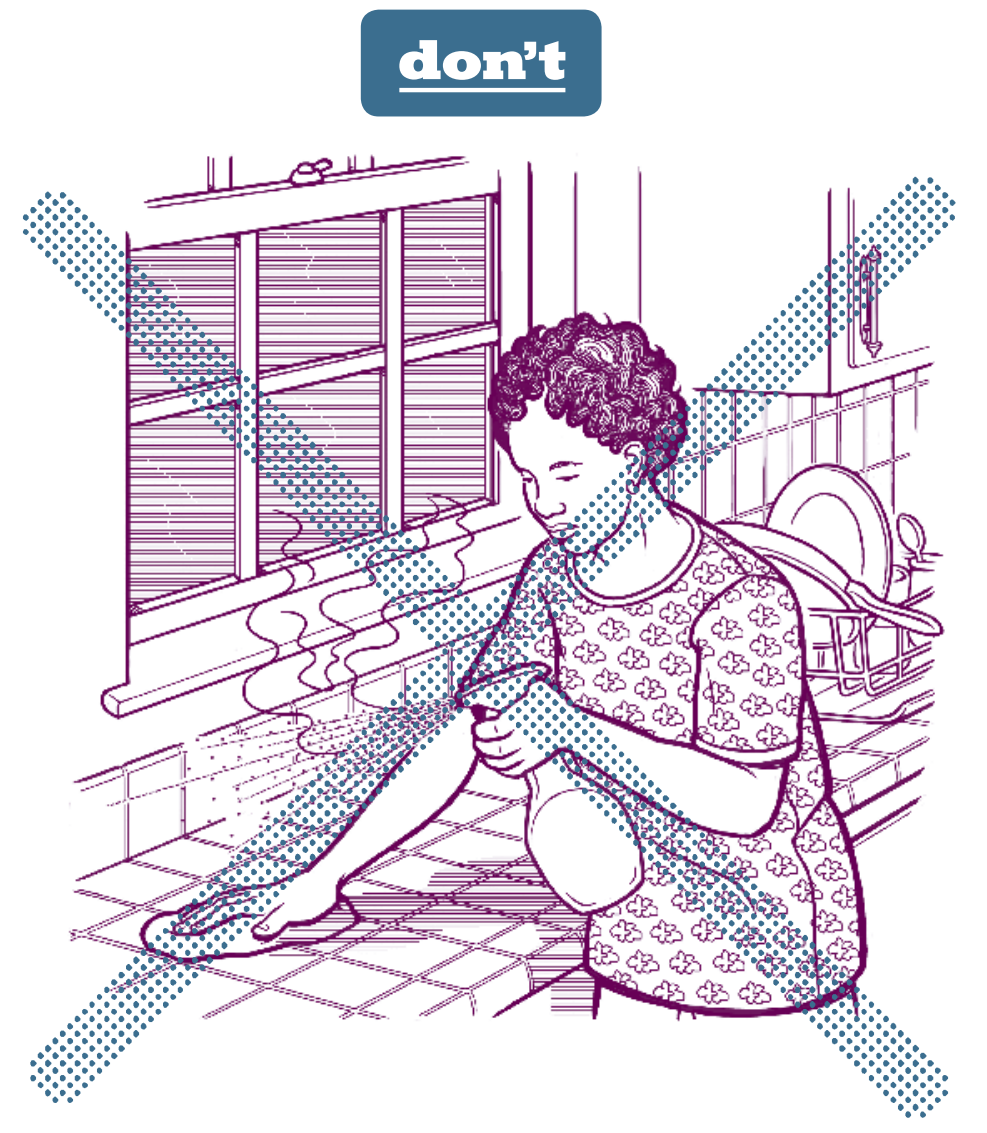

watch out for

Skin rashes or burns - Red, itchy eyes - Breathing trouble (wheezing, coughing, shortness of breath) • Headaches or dizziness

If you notice any of these problems, STOP using the product at once, wash up, and get fresh air! 


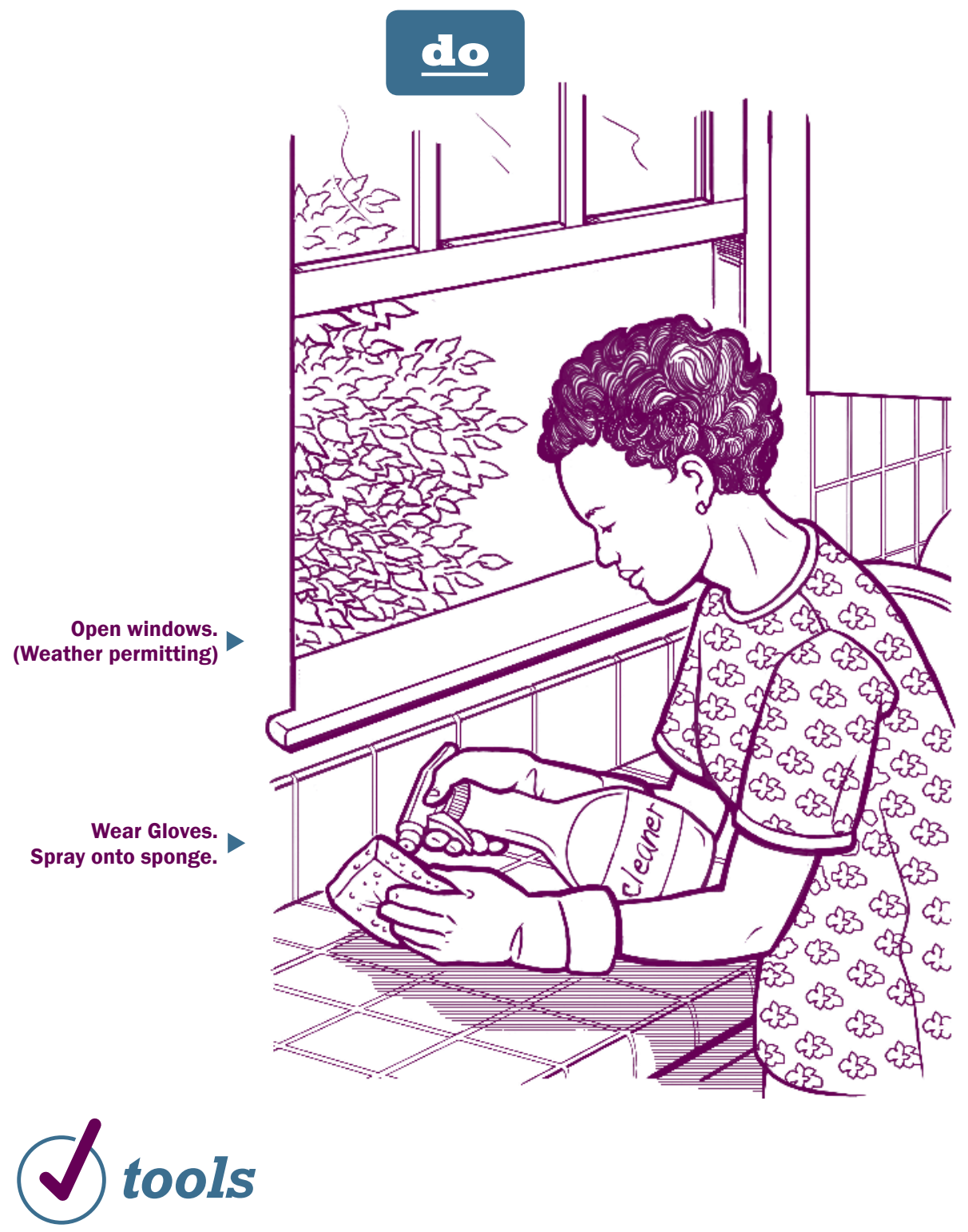

Use these things to make this work safer:

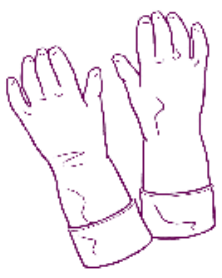

- Less harmful chemicals when possible. (You can make your own cleaners-see "Simple recipes for safer cleaners” on page 19.)

- Cleaning gloves to protect your skin. 


\section{tips}

- Keep products in their original labeled containers. If you make your own solution, write the contents on the bottle.

- Read labels and follow directions.

- Keep containers closed when not in use.

- Open windows and/or use a fan to get fresh air.

- Spray product on sponge rather than around the area to be cleaned.

- Don't mix different cleaning products. NEVER MIX bleach and ammonia!

The fumes can be deadly!

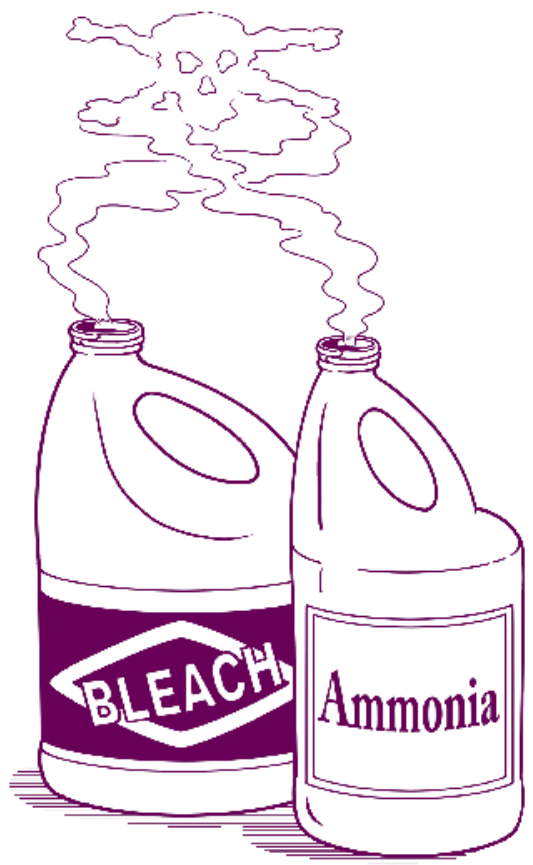




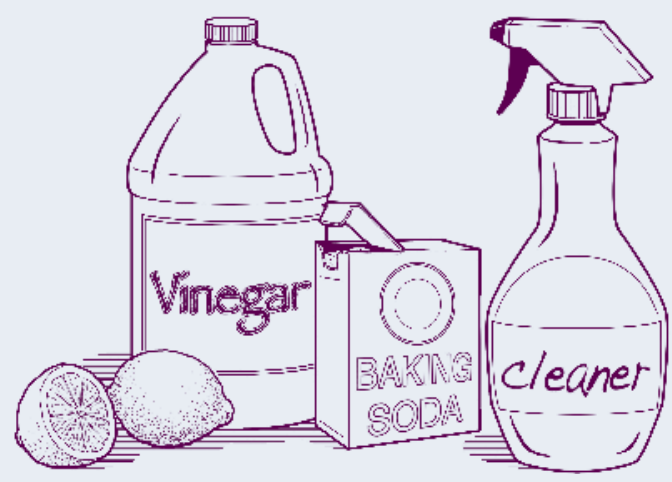

\section{Simple recipes for safer cleaners}

These cleaners work well and are simple to make from items found at the grocery store. Important: If you store them, label them!

\section{General cleaners}

- Mix 7 drops of dish soap in a standard size (24 ounce) spray bottle and fill with water. Cleans counters, floors, and walls.

- Mix baking soda with warm water. Cleans tubs, tiles, showers, and toilet bowls.

\section{Floor cleaner}

- Add a half cup white vinegar to a half gallon water. No need to rinse. Cleans linoleum and tile.

\section{Glass cleaner}

- Mix equal amounts of white vinegar and water. Rub windows with newspaper.

continues 


\section{Simple Recipes continued}

\section{Drain cleaner}

- Pour a half cup of baking soda down the drain, then a half cup white vinegar. Let sit for 15 minutes, and pour a pot of boiling water down the drain.

\section{Furniture cleaner and polish}

- Mix 1 part lemon juice with 2 parts olive or mineral oil. Use with a spray bottle and sponge or cloth.

\section{Oven cleaner}

(Do not use on self-cleaning ovens.)

- Mix 1 cup baking soda with water to make a paste. Apply to oven surfaces and let stand. Scrub with a scouring pad.

"We make a list at the beginning of the month to buy any necessary supplies to keep the house clean. We create the list together, and sometimes she suggests a substitute for something that bothers her. Then I buy what's on the list without hesitation." 


\section{talk it over}

You could say this: "This cleaning product can affect our breathing and irritate our eyes, but I can make another cleaner that is safer and works just as well."

\section{? find help}

- Grocery, drug, and hardware stores may carry cleaning gloves and safer cleaning products.

- For a poison emergency, call the Poison Control Center 1-800-222-1222.

\section{to do list}

Supplies needed:

$\square$ Cleaning gloves $\quad \square$ Less harmful cleaning products $\square$ Other:

New ways to do the tasks:

People or places we will contact for help, tools, or information: 


\section{Doing laundry for the client}

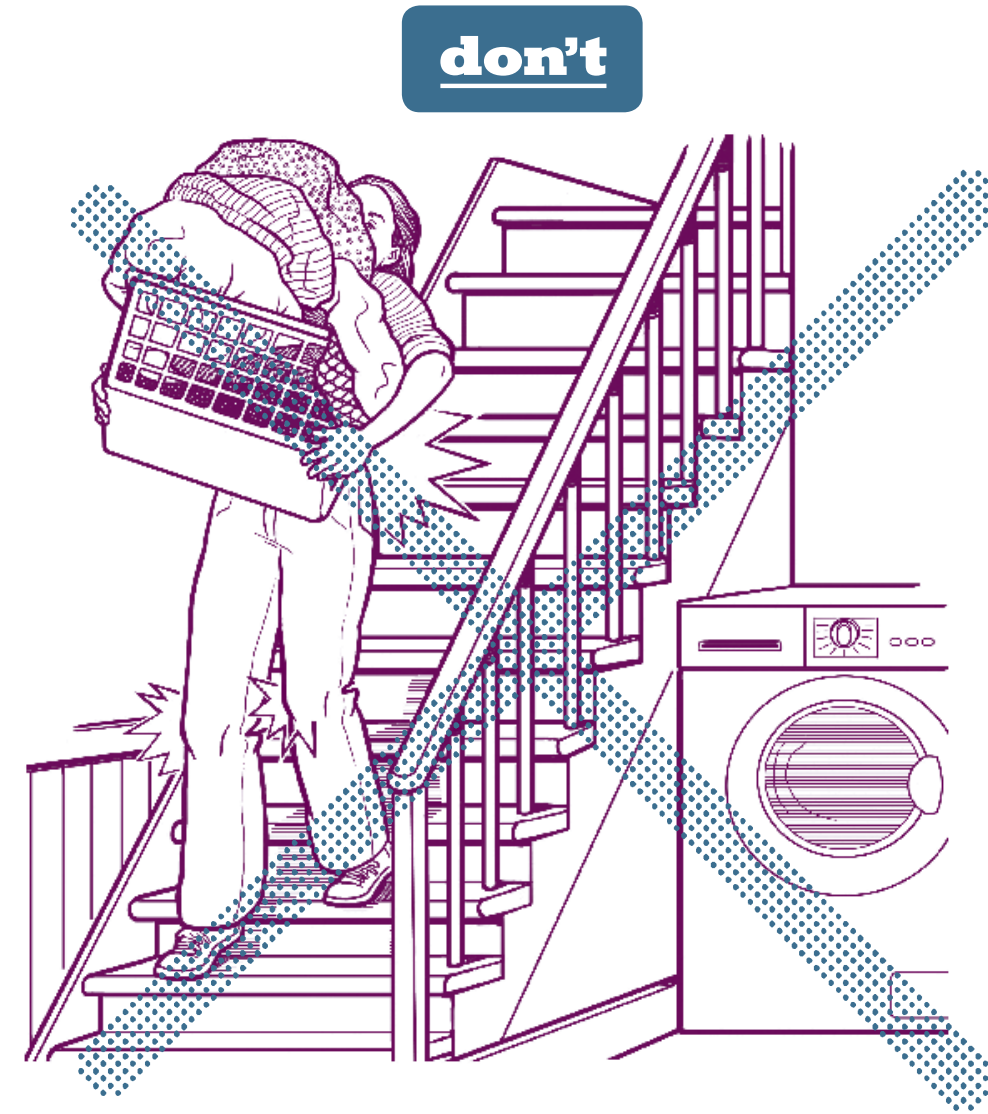

! watch out for

Exposure to infectious diseases from laundry soiled with body fluids - Aches and pains from lifting, carrying, and loading or unloading laundry 


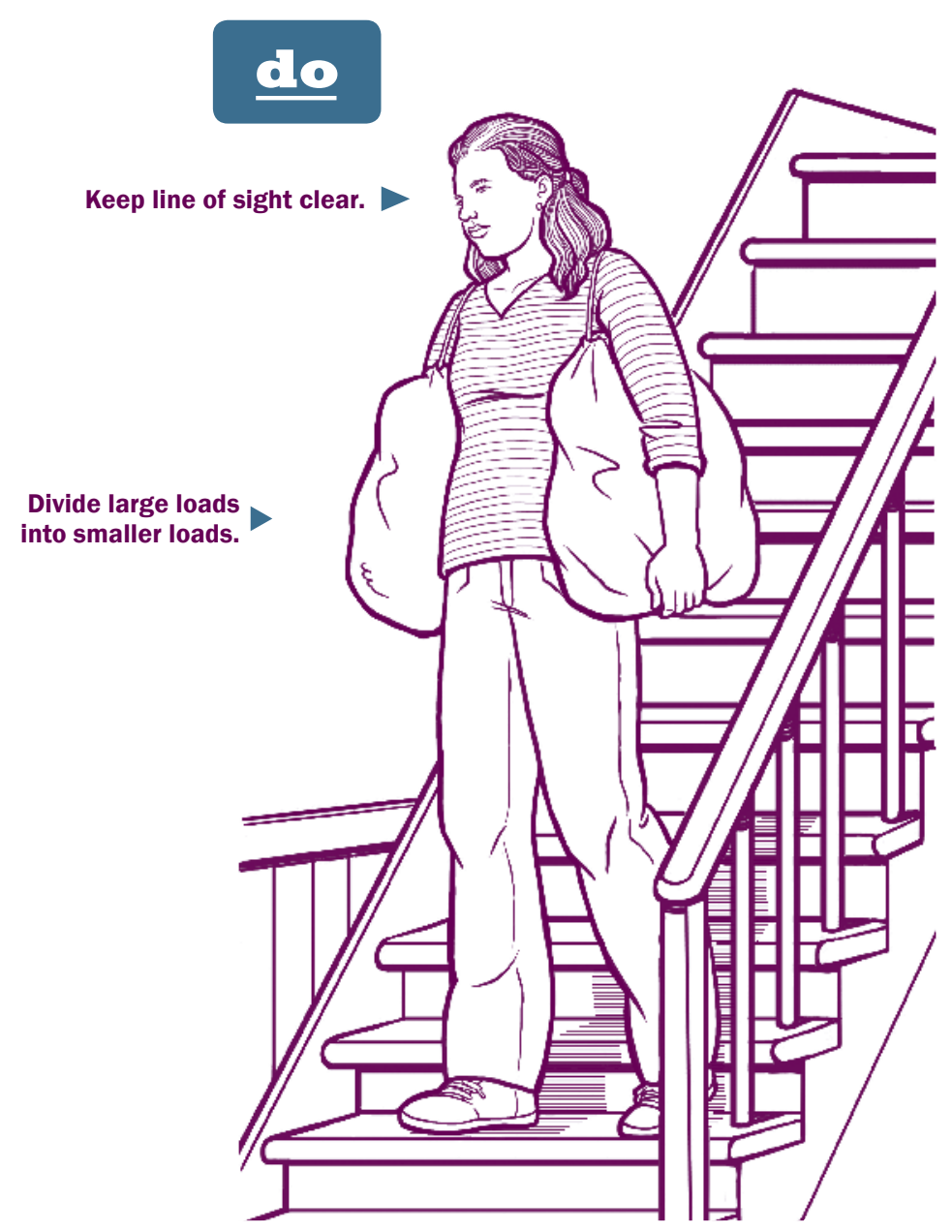

\section{tools}

Use these things to make this work safer:

- Pillowcases or laundry bags to carry small loads.

- Carts to transport heavy loads.

- Disposable gloves to protect your skin if blood or body fluids may be present.

- Heavy-duty plastic bags for carrying soiled laundry to protect your skin from contact with blood or body fluids. 


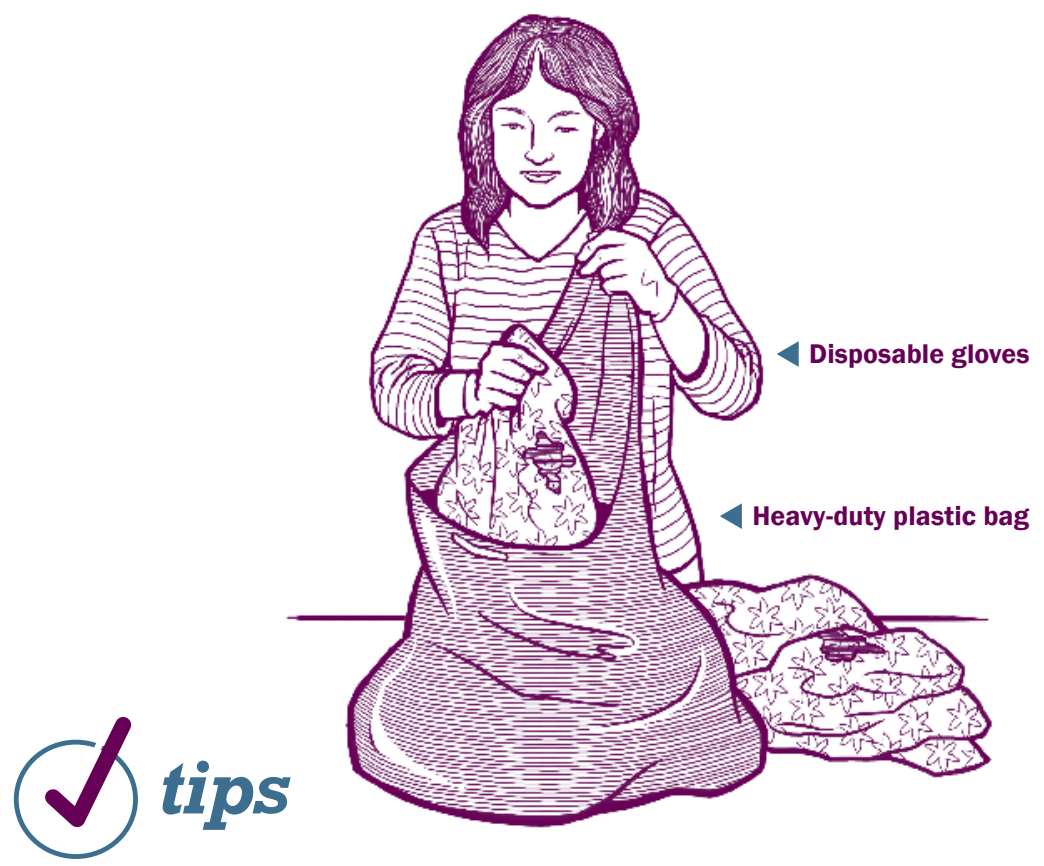

- Handle laundry that may be soiled with blood or body fluids carefully. Follow "Standard Precautions" on page 41.

- Tie laundry bags shut and make sure they don't leak.

- Keep your back as straight as possible when unloading items from a washer or dryer.

- Don't let the load you're carrying block your line of sight. You could trip or fall.

Divide big loads into smaller ones to make them lighter and easier to carry.

\section{talk it over}

You could say this: "It's hard on my back to carry

such a big laundry basket. Could we try to find a cart for me to use?" 
"When I got a cart, the worker could use it for both laundry and groceries."

Anna, client

\section{? find help}

- Hardware and discount stores sell plastic bags, gloves, aprons, and carts.

\section{to do list}

Supplies needed:

$\square$ Smaller laundry bags $\square$ Carts $\square$ Disposable gloves

$\square$ Heavy-duty plastic bags $\square$ Other:

New ways to do the tasks:

People or places we will contact for help, tools, or information: 


\section{Helping the client move from place to place}

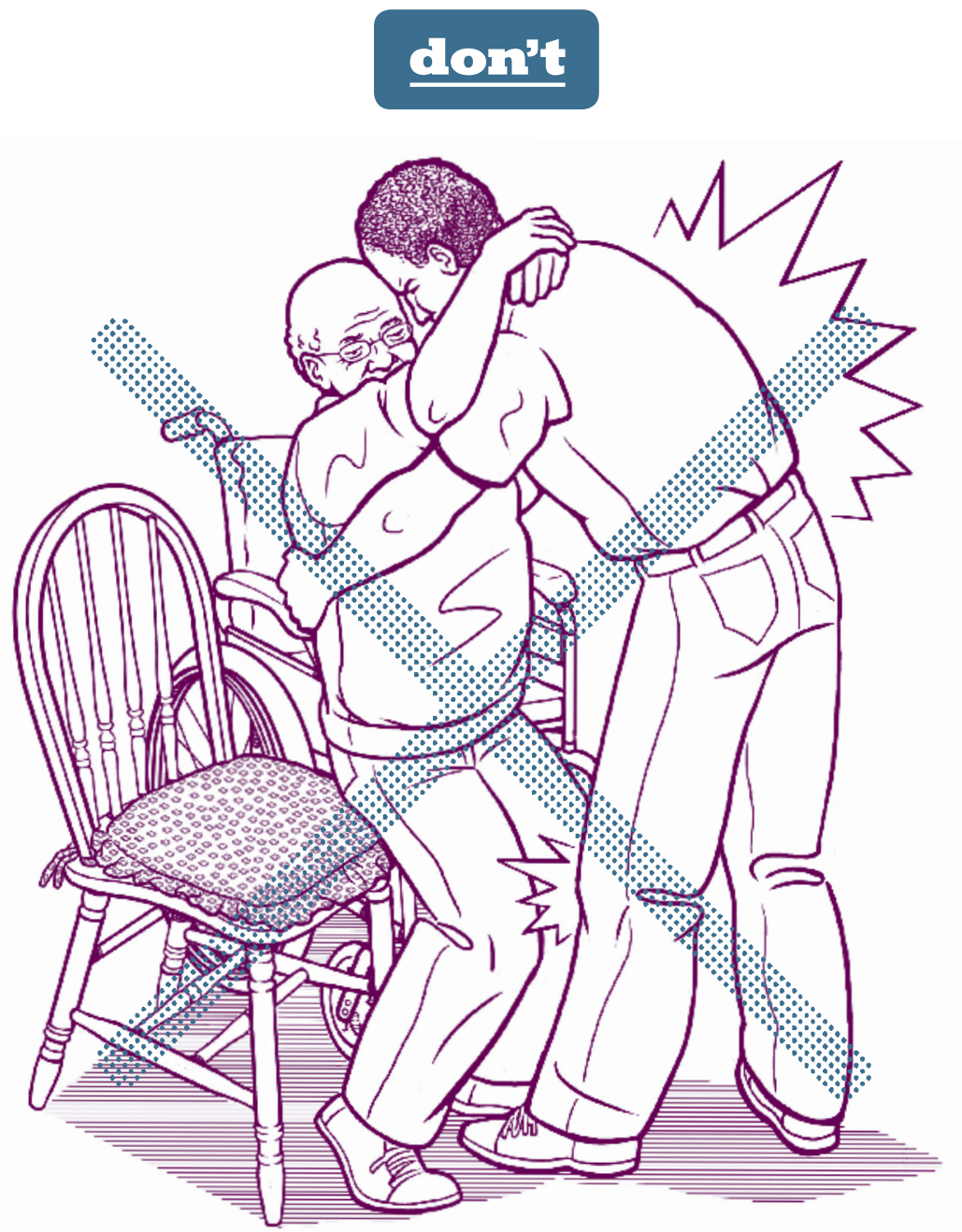

\section{! watch out for}

Back and shoulder injuries - General aches and pains 


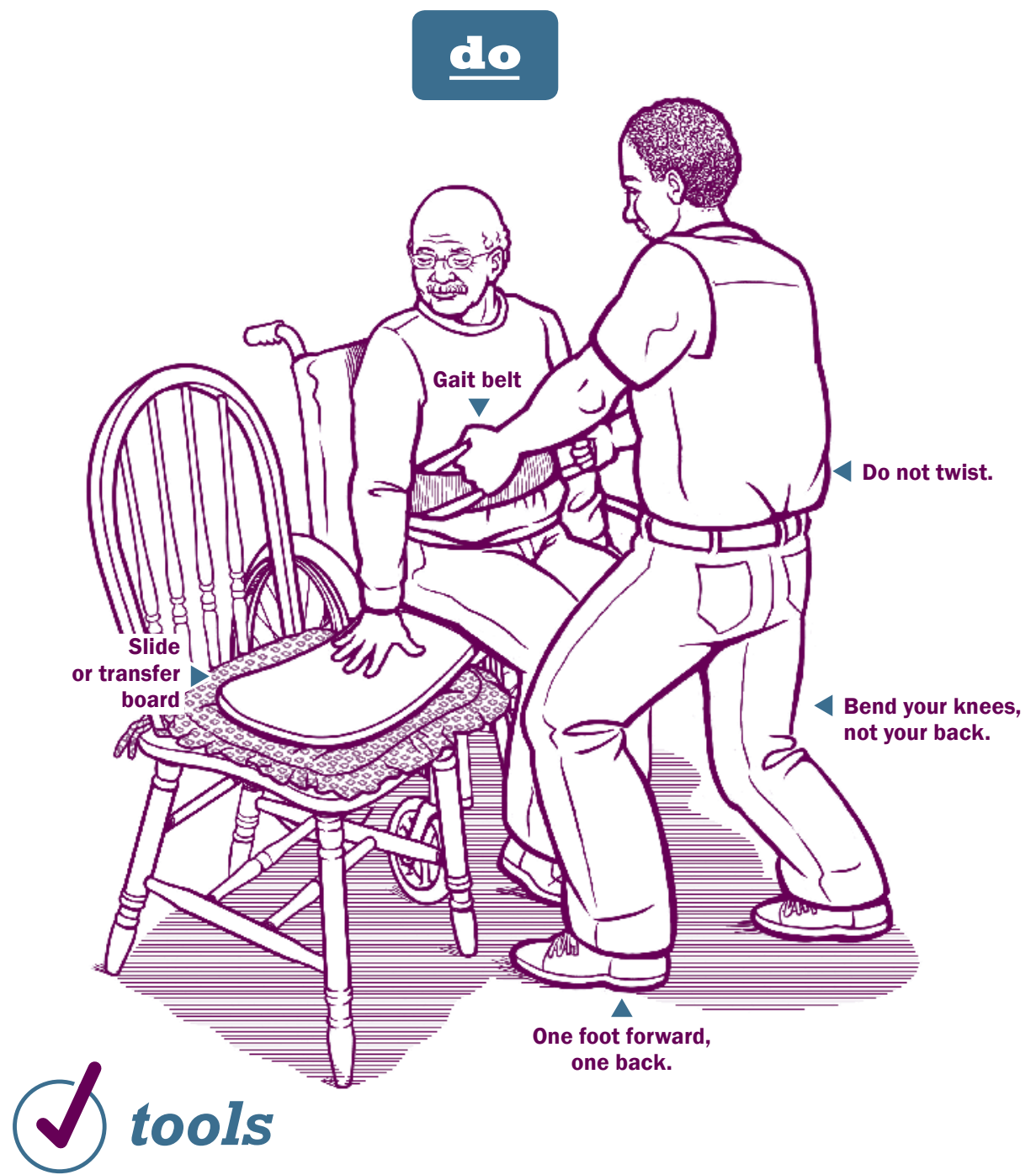

\section{Use these things to make this work safer:}

- A gait belt buckled around the client's waist is a simple, low-cost way to help with transfers and keep workers from straining their backs.

- A slide or transfer board to help the client move between two locations-such as a wheelchair and bed, or wheelchair and toilet. 


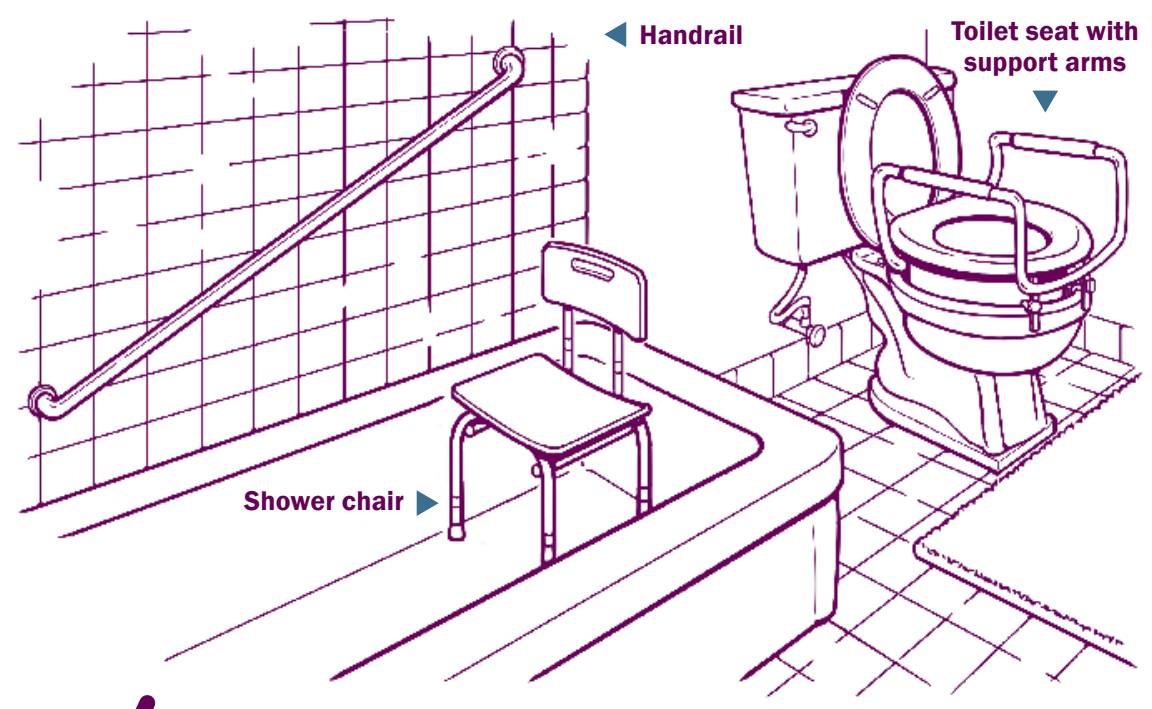

\section{tools continued}

\section{Use these things to make this work safer:}

- A Hoyer lift, which is a portable device that helps you lift and transfer the client.

- Handrails, grab bars, or vertical poles installed to help the client sit, rise, and stay upright.

- Shower chairs that let the client bathe more safely.

- Raised, lockable toilet seats with support arms to make bathroom visits easier and safer.

"I ask family members or former caregivers to come talk to a new caregiver. They can show what is safe and what is not." 


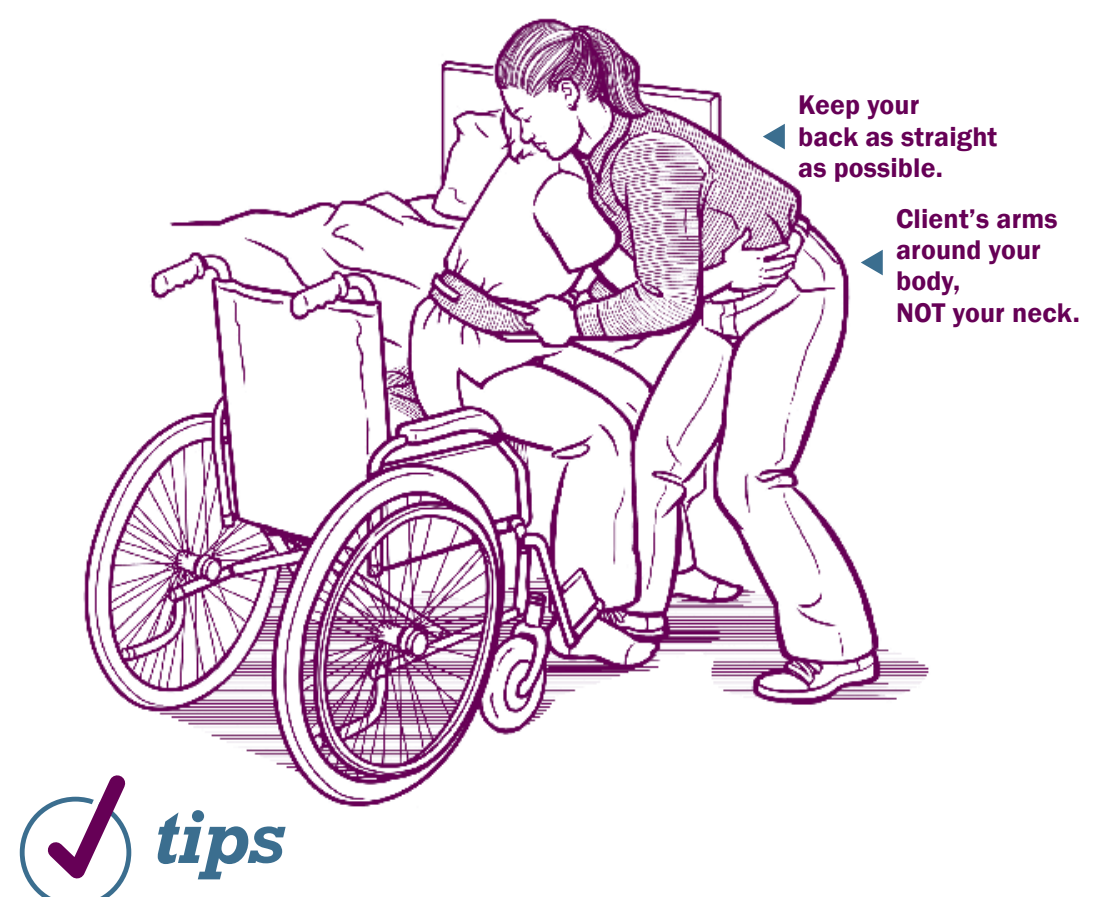

Use these safe-lifting practices:

- Don't try anything you think might be unsafe. If needed, get help from another person.

- Keep the client close to your body while you are assisting.

- Bend your knees-not your back-while moving him or her. Do not twist at the waist. Try to turn your whole body.

- Have the client put his or her arms around your body, NOT your neck.

- Do not pull with your arms or your back.

- Keep your feet at least as wide apart as your shoulders.

- Put one foot forward, the other back. 


\section{talk it over}

You could say this: "How are you usually moved? Tell me if there if there is anything special I should know. Can we work together to make it safe for my back?"

\section{When the client uses a wheelchair}

- Push, don't pull the wheelchair-it's easier on your back.

- Before helping with a transfer, remove or fold back the leg rests and make sure the brakes on both sides are locked.

- If the wheelchair is motorized, make sure the chair's power is turned off before the transfer so it doesn't accidently move and lead to an injury.

“At first, I didn't know how to help my client

in and out of bed, but my sister, who's also a homecare worker, suggested ways to do it safely. This made it much better. I had been going to a chiropractor a lot, but I didn't need to after I made a few changes."

Christine, homecare worker 


\section{If you're concerned that the client might fall}

- Have a plan in mind, including a number to call for help.

- If the client starts to fall, minimize the possibility of injury to both of you by controlling the fall-guiding the client slowly to the floor.

- After making sure that the client is not injured, assist him or her to rise or get help to lift the client.

\section{- If there's ANY POSSIBILITY} the client has been injured, DO NOT MOVE HIM OR HERCALL 911.

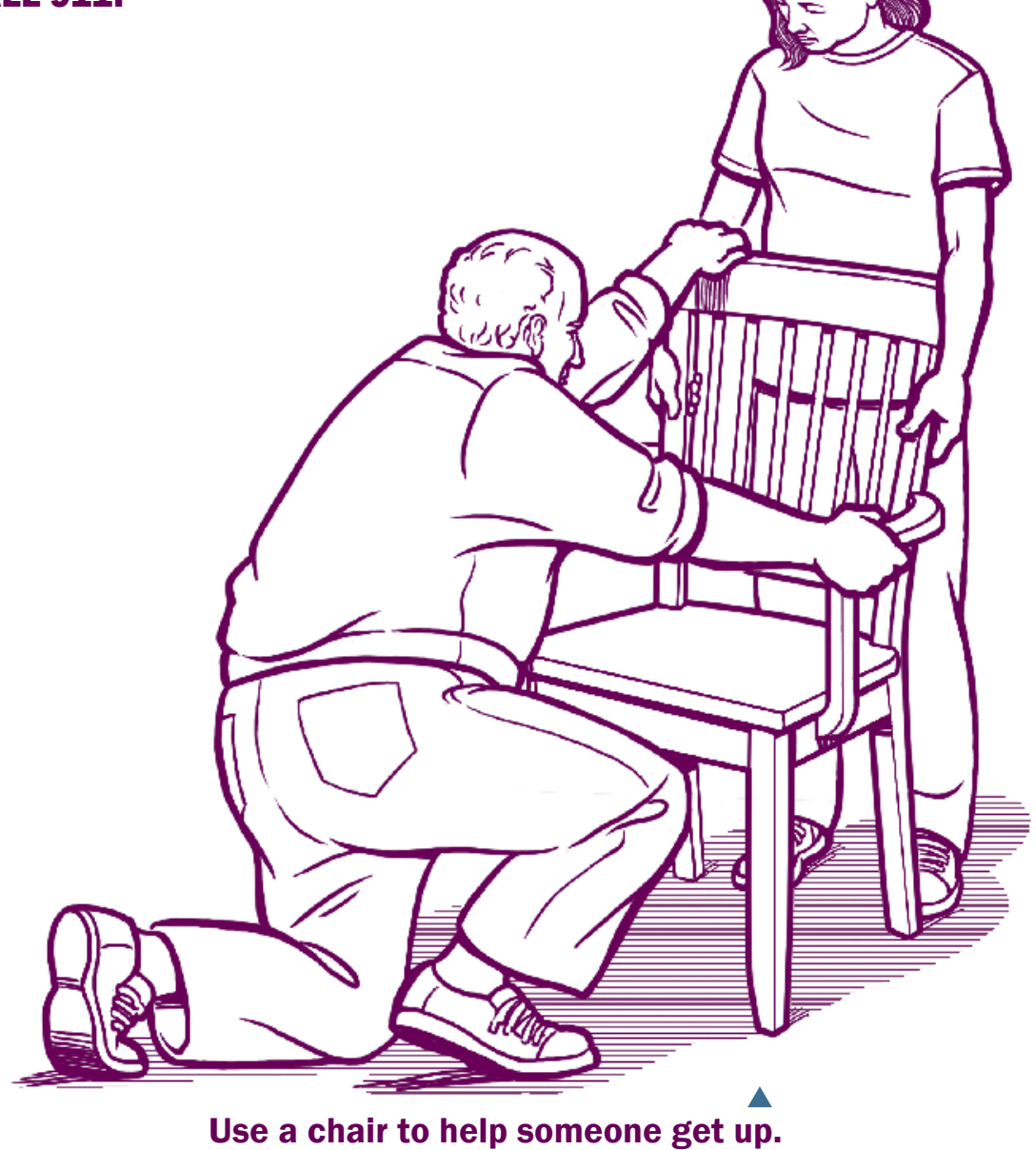




\section{find help}

\section{equipment}

- Clients can ask their doctors about getting a wheelchair, walker, cane, or other device to help them move around. Doctors can write prescriptions for these devices, sometimes called "durable medical equipment."

- Centers for Independent Living can also be helpful. Call 713-520-0232 (not toll free) to find a local center in your state. Or visit www.ilru.org.

- The Able Data website also has information about equipment at www.abledata.com.

\section{training}

- Local adult schools or community colleges provide Certified Nursing Assistant or homecare worker classes that cover lifting, transfers, and other procedures.

- If the client bought equipment from a medical equipment supply company, the company can show you how to use it.

- If you work for an agency, ask if they have training programs.

- Check with your union, if you have one, to see if they offer training classes. 
Supplies needed:

$\square$ Gait belt $\square$ Slide or transfer board $\square$ Hoyer lift

$\square$ Handrails, grab bars, or vertical posts $\square$ Shower chair

$\square$ Raised, lockable toilet seats with support arms

$\square$ Other:

New ways to do the tasks:

People or places we will contact for help, tools, or information: 


\section{Helping the client take a bath or shower}

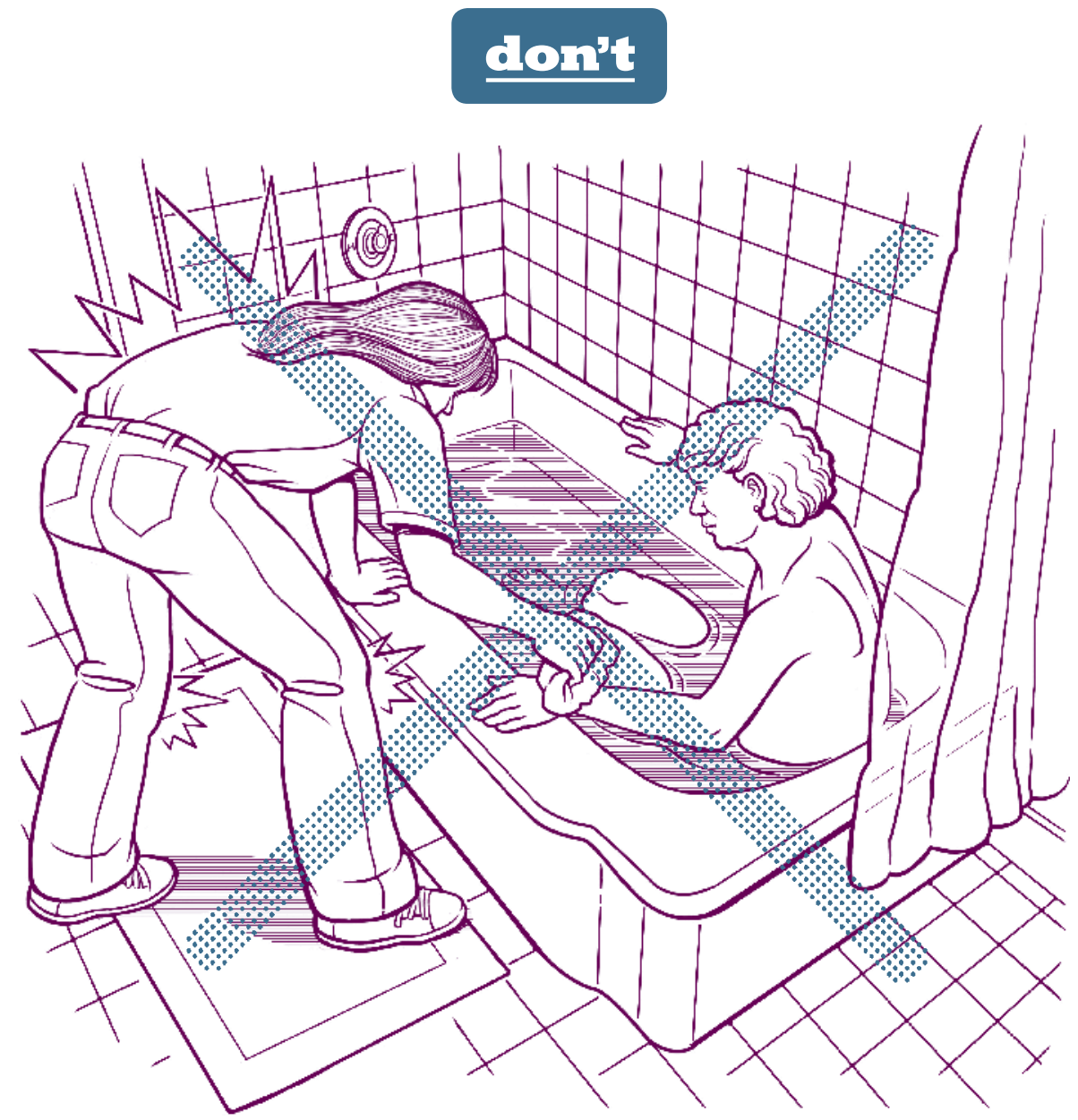

\section{! watch out for}

Muscle strains and sprains from lifting, transferring, and reaching - Exposure to infectious diseases 


\section{do}

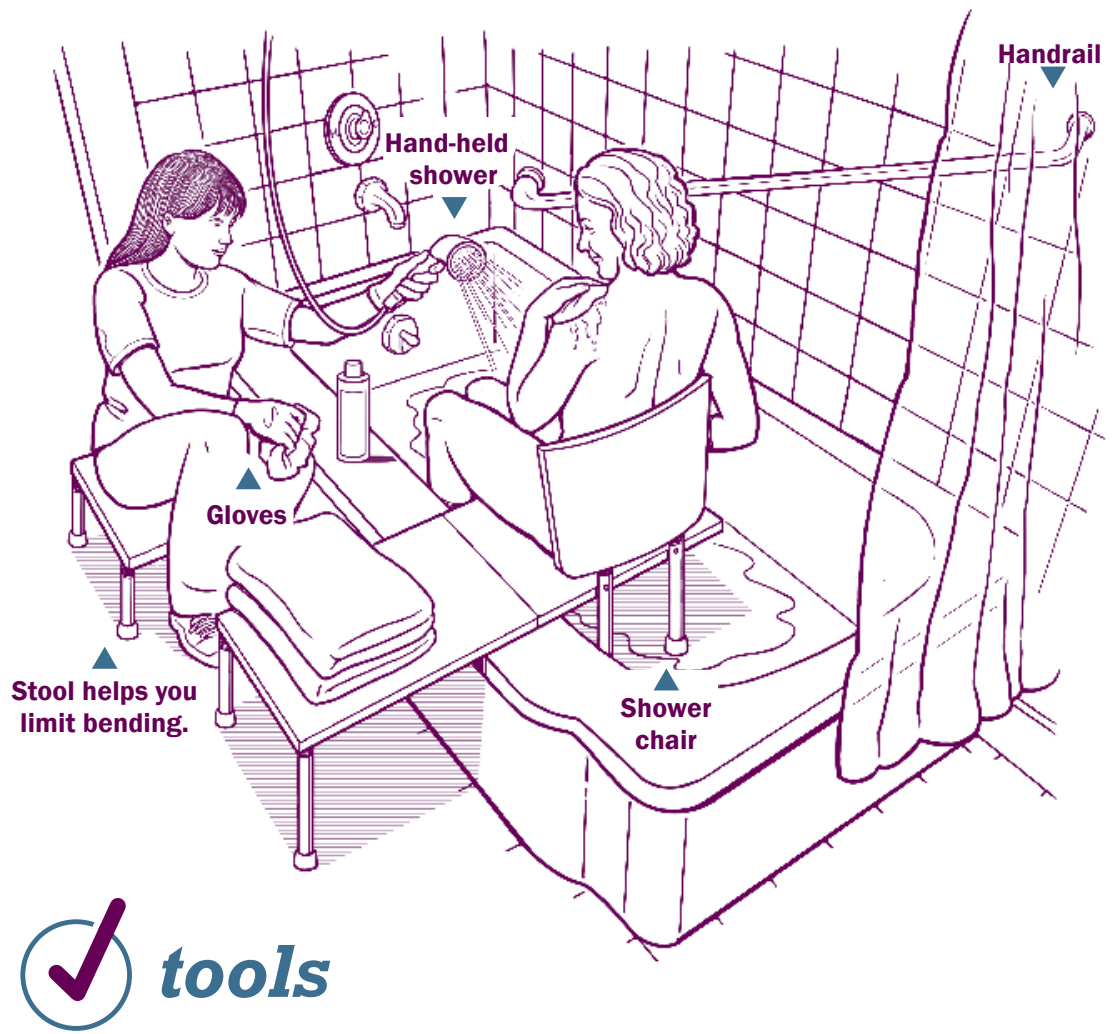

\section{Use these things to make this work safer:}

- Handrails installed for the client to use.

-A stool to sit on to keep you from reaching or bending too much.

- A shower chair to help the client bathe with less assistance.

- Disposable gloves should be worn any time there is a chance of contact with blood or body fluids. (See page 41 for "Standard Precautions.")

- A hand-held shower or shower hose to make bathing easier. 


\section{tools continued}

Use these things to make this work safer:

- A long-handled bath brush to limit reaching.

- Folded towels or bath mats to protect your knees if you're kneeling.

- A nonslip mat or tub strips to prevent falls or slips.

"I tell clients who live in apartments or senior housing to ask the building manager to install grab rails and removable shower heads."

Helen, homecare worker

\section{tips}

- Keep all your supplies (such as shampoos, soaps) nearby so you don't have to reach as much.

"I thought I might not like the feel of gloves against my skin, but I don't mind it, and it helps protect my worker's hands."

\section{talk it over}

Gabriel, client

You could say this: "I've heard that a shower chair can make taking baths much safer and easier. Some people have had luck asking their doctor for a prescription for a shower chair." 


\section{? find help}

Eldercare Locator can advise older persons and their families about equipment to help your client bathe or shower, use the toilet, and move around. This national service will connect callers to local service providers. Call 800-677-1116. Or visit: www.eldercare.gov

- Centers for Independent Living may also be able to help. Call 713-520-0232 ×130, www. ilru.org.

\section{- Medical equipment supply companies may} accept a prescription from a doctor for shower chairs.

- Local drug stores and discount stores sell products that help in bathing and showering.

\section{to do list}

Supplies needed:

$\square$ Nonslip mat or tub strips $\square$ Handrails $\square$ Stool

$\square$ Long-handled bath brush $\square$ Shower chair

$\square$ Disposable gloves $\square$ Handheld shower or shower hose $\square$ Other:

New ways to do the tasks:

People or places we will contact for help, tools, or information: 


\section{Fandling needles and sharps}

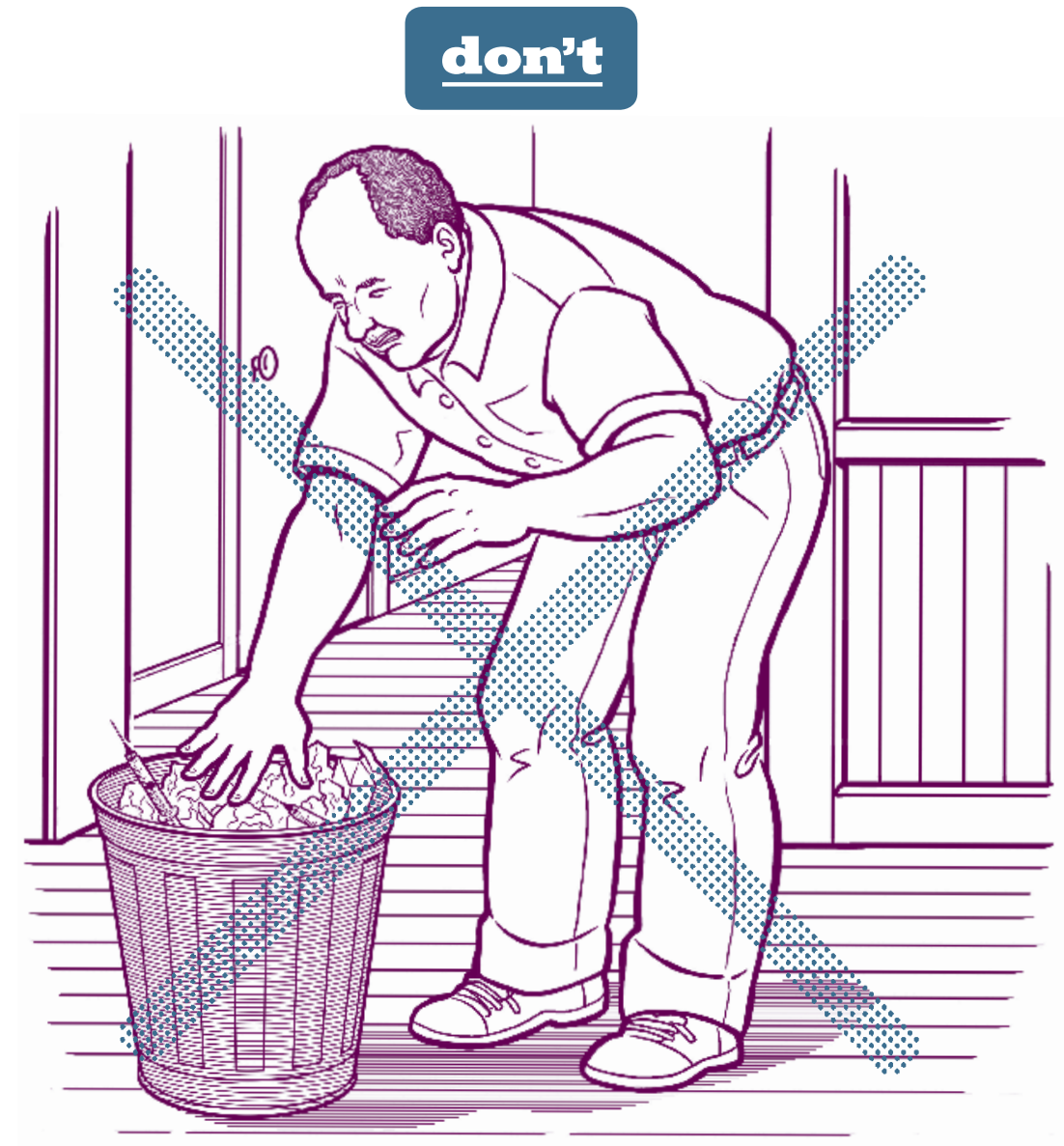

\section{! watch out for}

Contact with blood and body fluid. They can be infected with disease. Diseases carried in blood include HIV, the virus that causes AIDS, and hepatitis B and C, which are incurable liver diseases. 


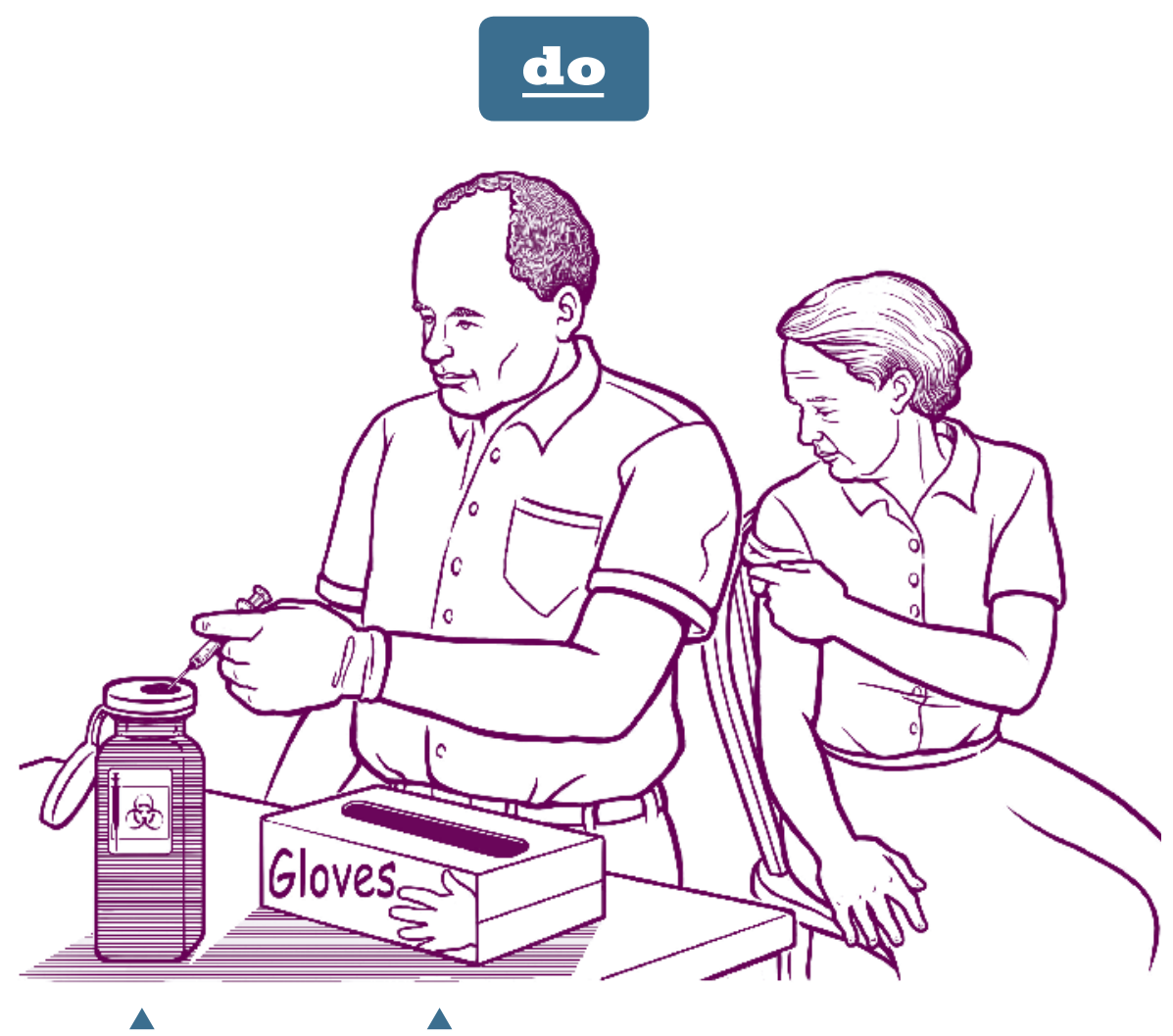

Sharps container Disposable gloves

\section{You are at risk for HIV/AIDS, hepatitis,}

\section{and other diseases if you}

- Are stuck by a needle or "sharp" (an object that can

pierce your skin) that has infected blood on it. It could be a needle that you are using for an injection, a diabetes stick, a discarded needle that accidentally sticks you when you are cleaning up trash, a razor, or a piece of broken glass.

- Are splashed in the eyes with infected blood.

- Touch infected blood when you have a cut, open sore, or broken skin.

Clients may also be at risk of getting an infectious disease from homecare workers. 


\section{tools}

\section{Use these things to make this work safer:}

- Disposable gloves.

- A sharps container for throwing away used needles or other sharps.
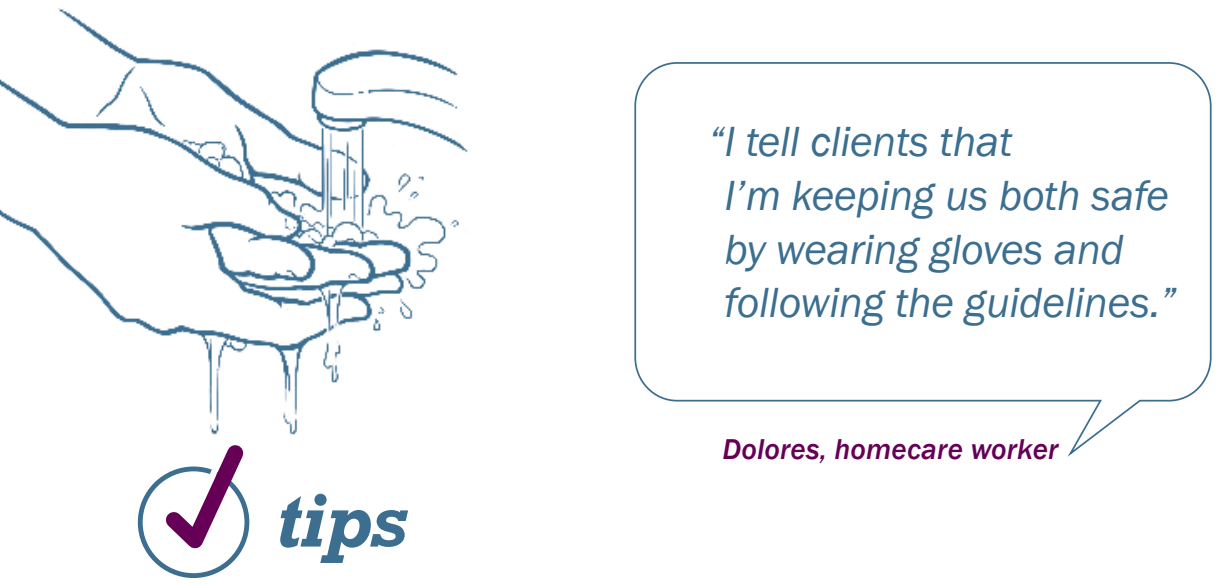

- If you get a needle stick or a cut from a sharp, wash the area with soap and water. If the contact is with your nose, mouth, or skin, flush with water. If it is with your eyes, rinse them with clean water or saline. Contact your doctor as soon as you can.

- If you work for an agency or company, immediately report this accident to your employer.

"I provide gloves-even masks-and clean towels. I want the homecare worker to use them. If they're coughing or something else, I would like them to put on a filter mask." 


\section{Standard Precautions}

You can't tell if people are infected with HIV or hepatitis B just by looking at them. Using "Standard Precautions" means protecting yourself as if all blood and body fluids are infected. Use Standard Precautions whenever there is a chance of contact with blood or body fluids, including during tasks such as bathing, wound care, laundry, and toileting.

1. Wear disposable gloves every time you may be in contact with blood or body fluids. Ask the client about skin allergies to specific products. Use special gloves if either of you is allergic to latex or vinyl.

- Make sure the gloves fit. Replace them if they get torn or damaged.

- Use new gloves for each new client and each new task. NEVER reuse disposable gloves. Throw away used gloves.

- Wash your hands before you put on gloves and after you take them off. NEVER touch your mouth or eyes while wearing used gloves.

- Turn gloves inside out when removing them. Put them in a plastic bag and tie the bag for disposal.

2. Wash your hands often.

- Wash with soap and running water at regular times during your work.

- Remove any blood or body waste from your skin or the client's skin by washing with soap and running water. 


\section{Standard Precautions continued}

3. Handle sharps with extreme care.

- Point sharps away from your body and discard them immediately after use into a sharps container. Never put sharps in a regular recycling bin or trash can.

- Never reach into a trash bag! It could contain needles or other sharps.

\section{- Never recap a needle or touch the point.}

4. Cover cuts, sores, or breaks in your skin and the client's skin with bandages, unless the doctor says otherwise.

5. Use bleach to carefully clean household surfaces that may have blood or body fluids on them. Mix one part bleach to 10 parts water. Make this solution fresh each

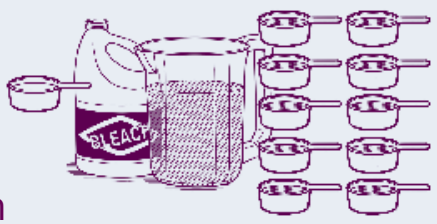
day-and label it.

6. Get a vaccination to protect you from Hepatitis B (See find help section, below).

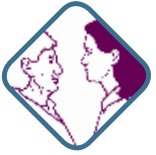

\section{talk it over}

You could say this: "I always use gloves when I help clients take their blood sugar test (or another task that could expose you to infection). As homecare workers, we have to be very careful to protect ourselves from serious problems."

\section{? find help}

- Disposable gloves are available at grocery stores, drugstores, and medical supply stores.

- Check with your doctor or clinic about getting a Hepatitis B vaccination. 
- If you work for an agency or company, ask your employer to arrange for free and confidential hepatitis B vaccinations and flu vaccinations from an independent health care provider. If you are in a union, ask your union to arrange this. If you don't have health insurance, call your city or county health department to find out where you can get vaccinated.

-To get a sharps container, contact your medical provider, drugstore, or medical supply store.

Ask them how to properly dispose of the used container.

\section{to do list}

Supplies needed:

$\square$ Disposable gloves $\quad \square$ Sharps container $\quad \square$ Bandages

$\square$ Bleach $\square$ Other:

New ways to do the tasks:

People or places we will contact for help, tools, or information: 


\section{Cooking and shopping for the client}

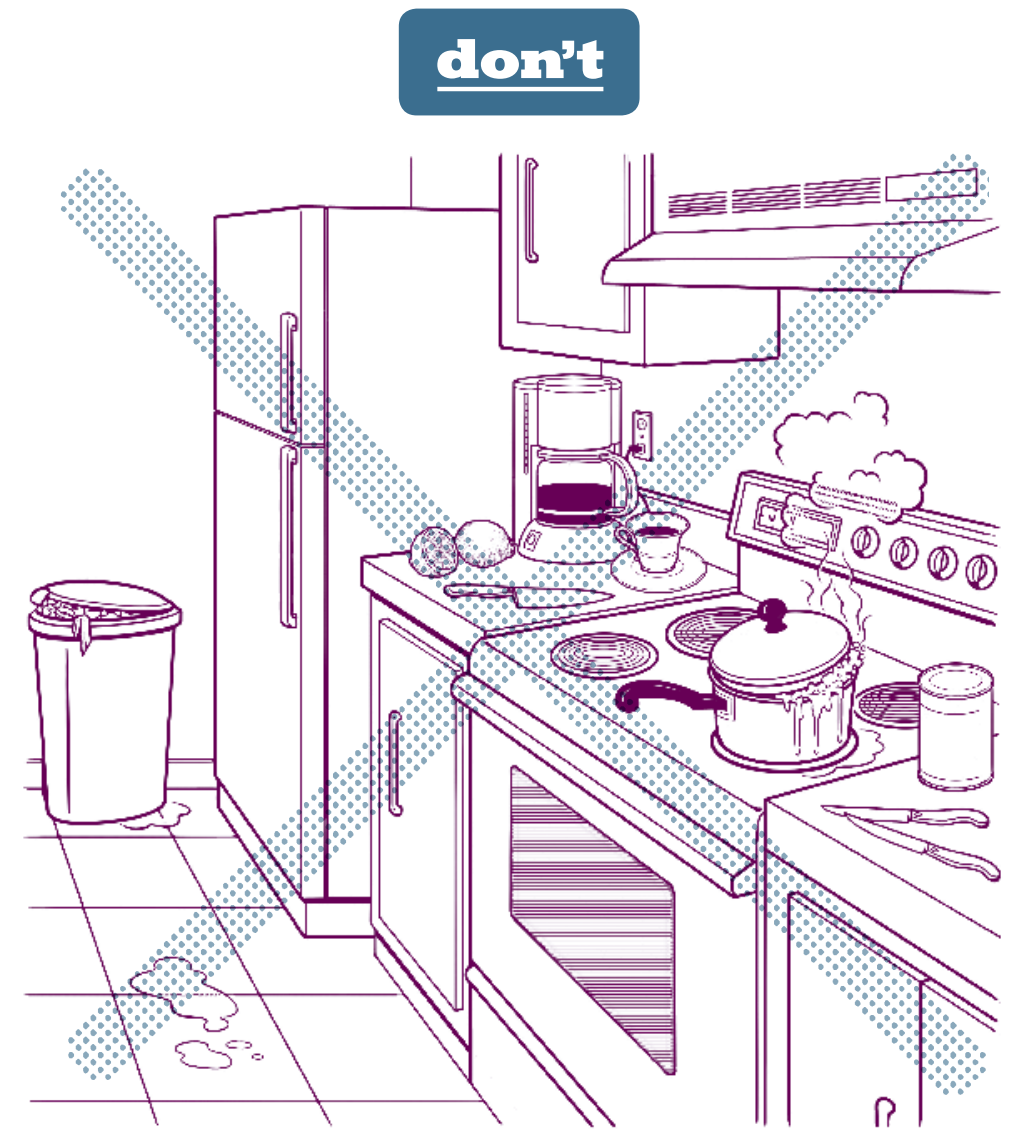

!

watch out for

Burns - Fires - Cuts from knives - Muscle strains and sprains from reaching and lifting - Slips and falls from spills 


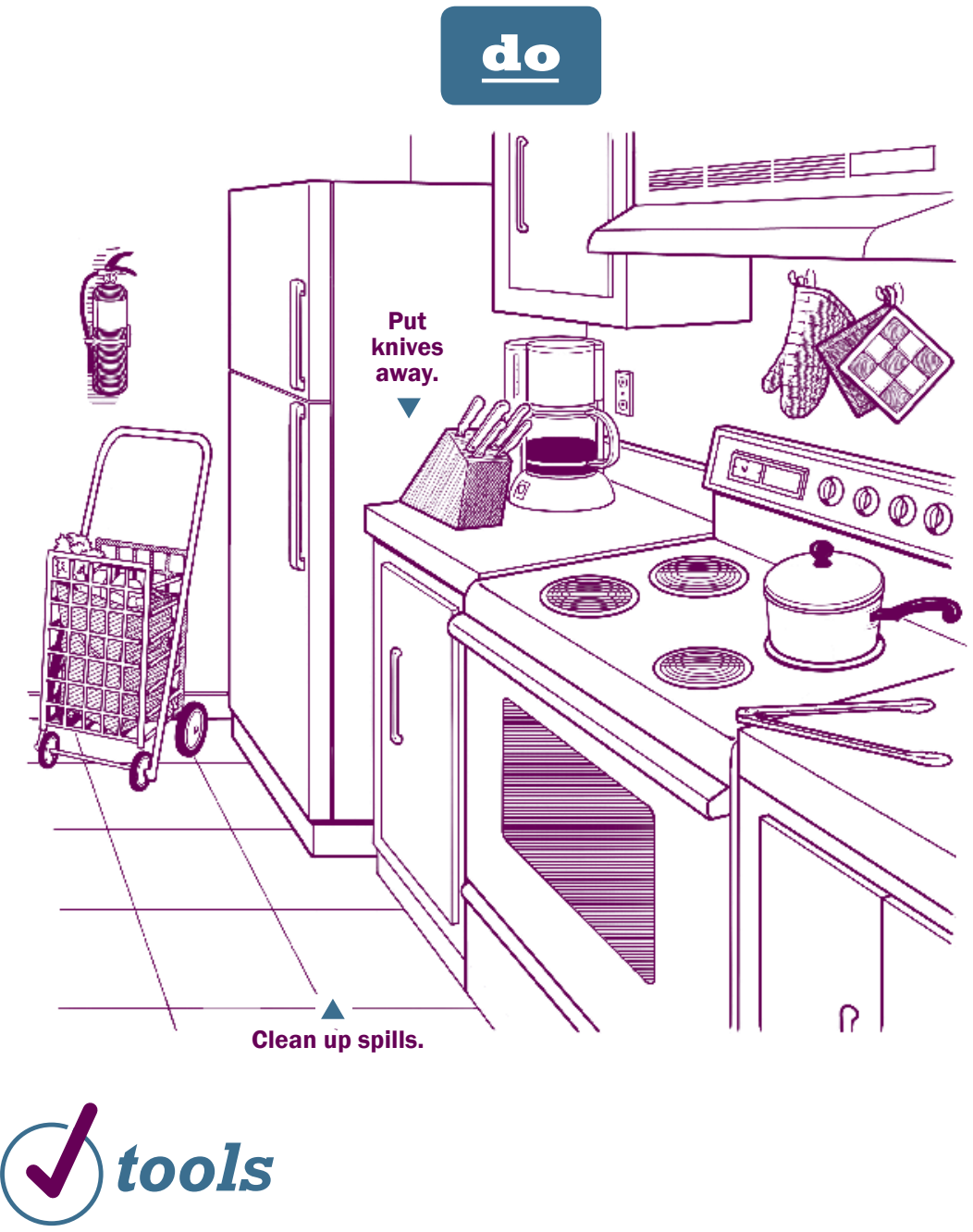

Use these things to make the tasks safer:

- Potholders, gloves, or mitts when handling food on the stove or in the oven.

- Stepstools to reach items overhead.

- Carts to carry groceries or other heavy items.

- Tongs to lower food into boiling water.

- Fire extinguishers labeled as $B, B-C$, or A-B-C for flammable liquids. 


\section{tips}

\section{Knives}

- Store knives safely.

- If you are interrupted while cutting something, lay the knife down in a flat, safe space.

- Let a falling knife fall. Never try to catch a falling knife.

\section{Stoves}

- Set pot handles away from burners.

Lift pot covers slowly, away from your face, to protect yourself from steam.

- Never leave hot oil or grease unattended.

- Don't leave the room while a burner is on. Fires can start when the liquid evaporates or food gets too hot.

\section{- NEVER pour water on a cooking fire!} Use a fire extinguisher that is rated for flammable liquids or put a lid on the pan and turn off the heat. Don't take the lid off until the pan is completely cooled.

- If there's a fire in the oven, turn off the oven, keep the oven door closed and phone 911 for help. 


\section{Shopping}

- Limit the amount you carry by hand. Use a cart if possible.

- Follow safe lifting and carrying guidelines.

- Keep your back as straight as possible and use your legs while lifting.

- Make sure bags are light and easy to carry.

\section{Storing and moving items}

- Store heavy and frequently used items at waist height, if possible, to reduce reaching and bending.

Move heavy items one at a time.

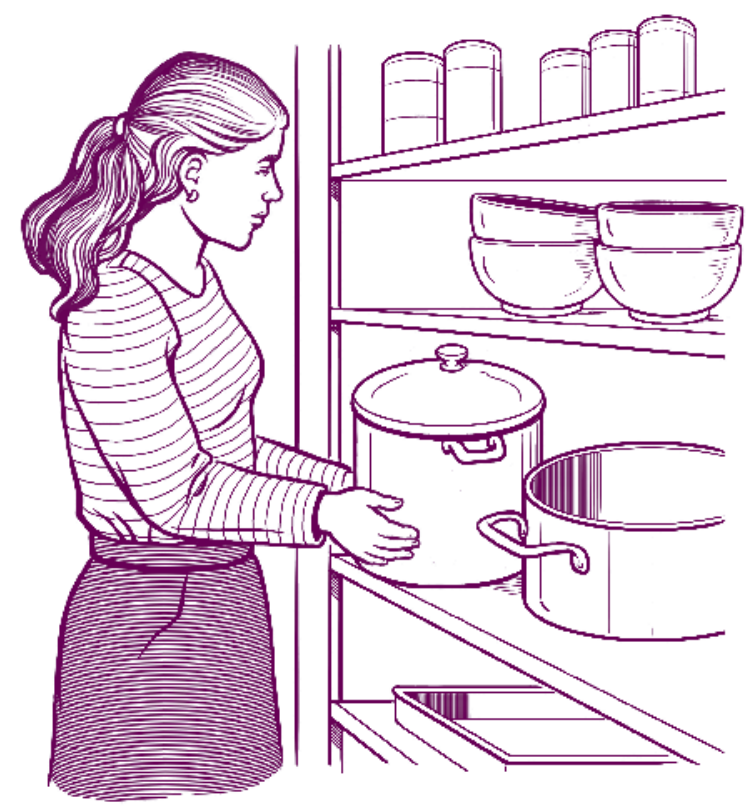


"When my homecare worker used to buy groceries for me, she would carry the groceries to my house from the market. Now when we shop, I borrow a cart from my neighbor. This makes it easier for her -she no longer has to carry heavy grocery bags to my house."

Ling, client

\section{talk it over}

You could say this: "If we move these items to a lower shelf, I won't have to reach so high. Do you mind if I do that to protect my back?"

\section{? find help}

- You can buy potholders, cooking gloves or mitts, stepstools, grocery carts and tongs at most hardware and discount stores. 


\section{to do list}

Supplies needed:

$\square$ Potholders, gloves, or mitts $\square$ Stepstools $\square$ Carts

$\square$ Tongs $\square$ Fire extinguishers labeled B, B-C, or A-B-C $\square$ Other:

New ways to do the tasks:

People or places we will contact for help, tools, or information: 


\section{Preventing trips and falls}

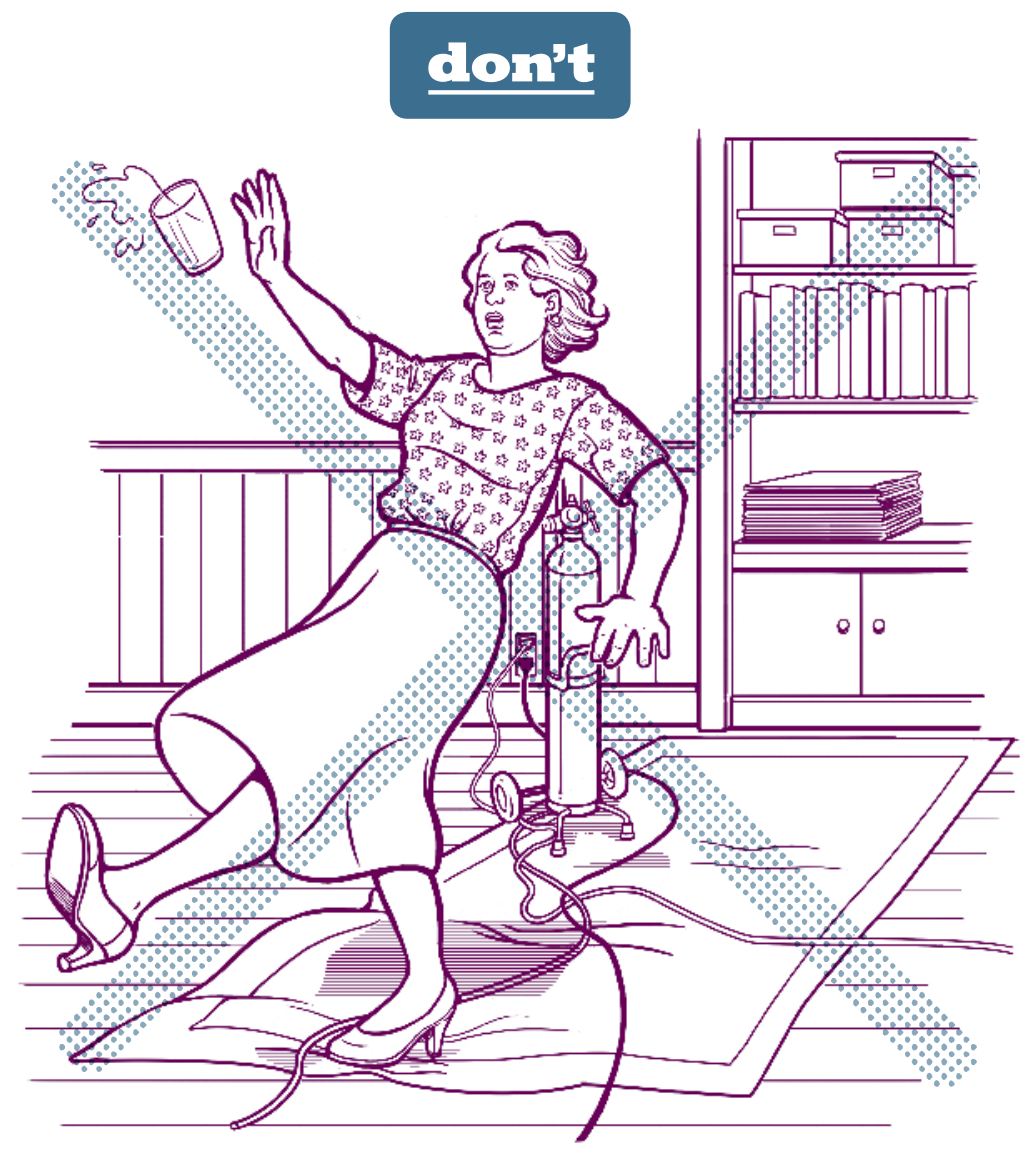

! watch out for

Bruises and sprains $\bullet$ Broken bones 


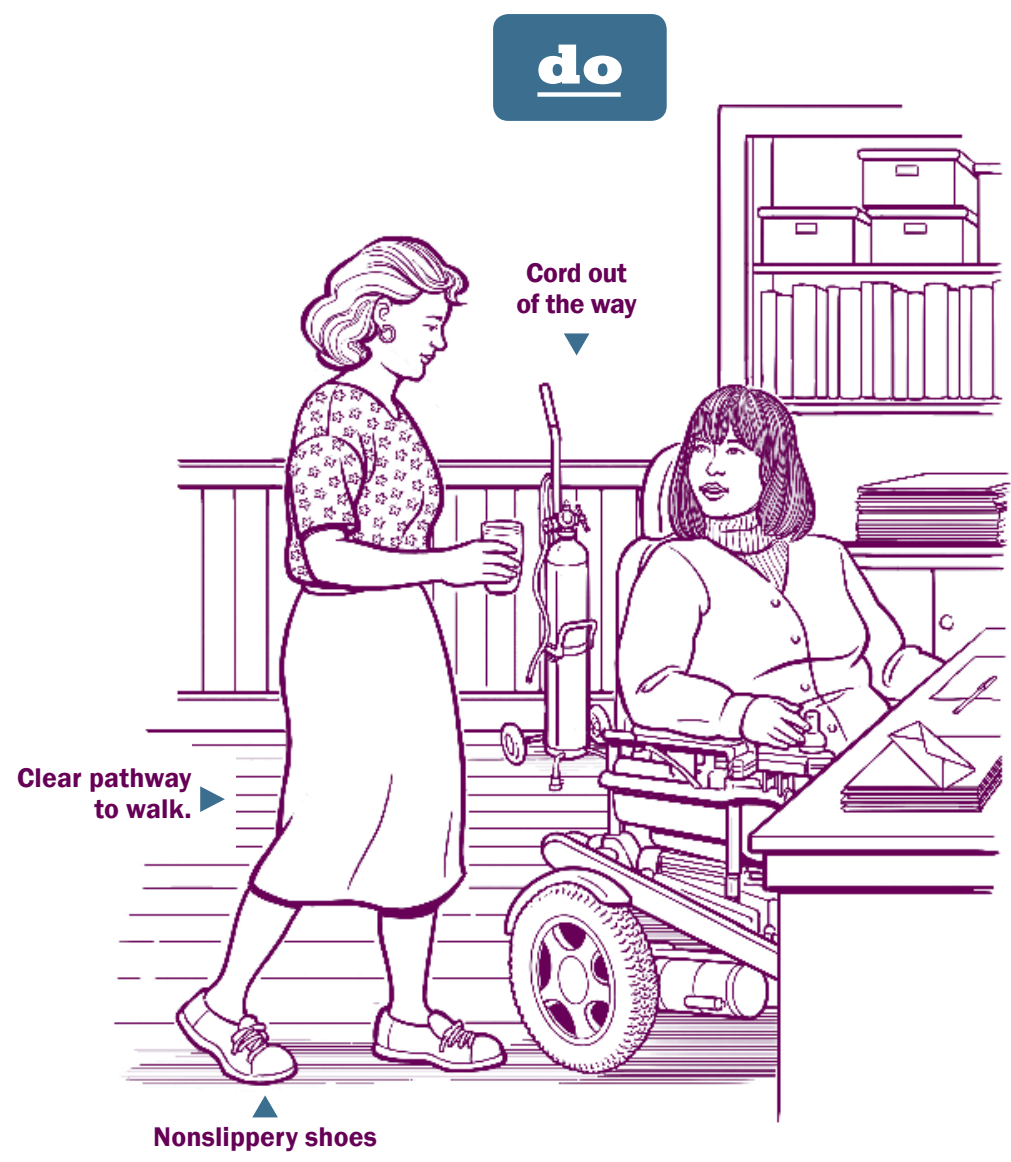

$\checkmark$ tools

Use these things to make the tasks safer:

- Shoes with nonslip soles.

- Carpet fasteners or double-sided carpet tape to help keep rugs in place.

- Adequate lighting throughout the home, including walkways, stairs, and outdoor areas. Make sure all light bulbs are working.

- Keep flashlights on hand in case of power outages. 


\section{tips}

- Use nonskid wax on floors or no wax at all.

- Clear walkways and stairs of obstacles and tripping hazards like boxes, papers, and other items.

- Move or remove items that might cause falls, such as these:

- Electric cords from phones, lamps, radios.

- Curled or wrinkled rugs, mats, or carpets.

- Oxygen tubing.

- Keep a mop and towels on hand to clean up spills quickly. (Remember that dry spills, such as flour, sugar, and coffee grounds can also lead to falls.)

- Sweep or vacuum the floor regularly.

- Never leave drawers open on dressers, file cabinets, or other furniture.

\section{Of special concern}

Always ask clients for permission before moving their belongings. This is especially important for clients with memory or vision disabilities. 


\section{tips continued}

- On stairs, use railings and take your time. Make sure your vision is not blocked by anything you carry.

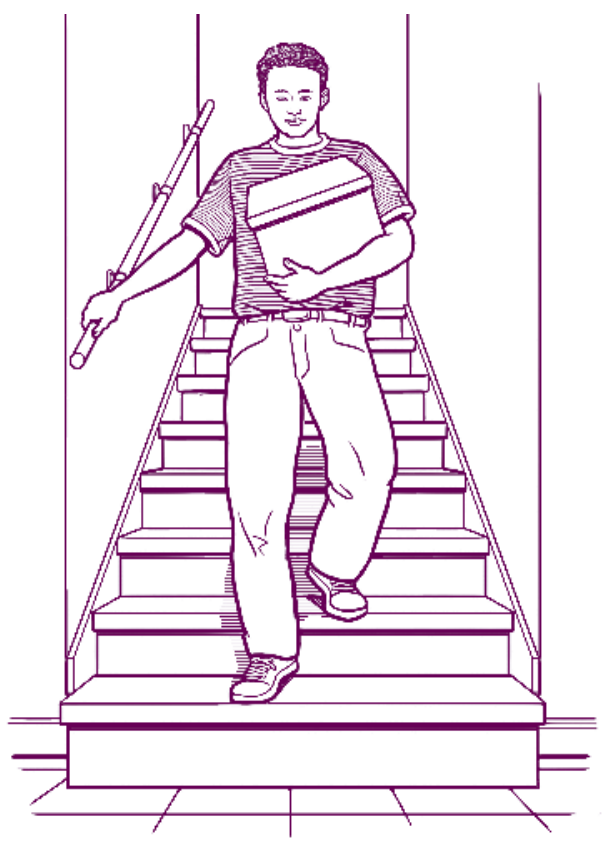

Do not place throw rugs at the top or bottom of stairs.

\section{talk it over}

Be sensitive that the client may not want the house and its contents rearranged.

You could say this: "I know you might not like having your things moved, but we need clear pathways so neither of us will get hurt. What could we do to make this area safer?" 
"Rugs on the floor are a big problem. If the worker doesn't trip, then I might. Homecare workers don't want to get hurt, and they don't want the clients to get hurt-especially seniors like me, who may take a long time to heal."

Paul, client

\section{find help}

-These websites offer more information:

- Eldercare Locator. www.eldercare.gov. Toll-free nationwide: 1-800-677-1116

- Centers for Disease Control and Prevention. www.cdc.gov/homeandrecreationalsafety

- AARP. www.aarp.org. 1-888-OUR-AARP

(1-888-687-2277)

Toll-free TTY: 877-434-7598

Toll-free Spanish: 877-MAS-DE50

(877-627-3350)

- Center for Healthy Aging, National Council on Aging. www.healthyagingprograms.org.

- NIOSH Fast Facts for Home Healthcare: 2012-118, 2012-119, 2012-120, 2012-121, 2012-122, 2012-123. www.cdc.gov/NIOSH.

- Local stores sell flashlights, batteries, mops, and carpet fasteners. 


\section{to do list}

Supplies needed:

$\square$ Shoes with nonslip soles

$\square$ Carpet fasteners or double-sided carpet tape

$\square$ Flashlights $\square$ Other:

New ways to do the tasks:

People or places we will contact for help, tools, or information: 


\section{Fire and electrical safety}

\section{don't}

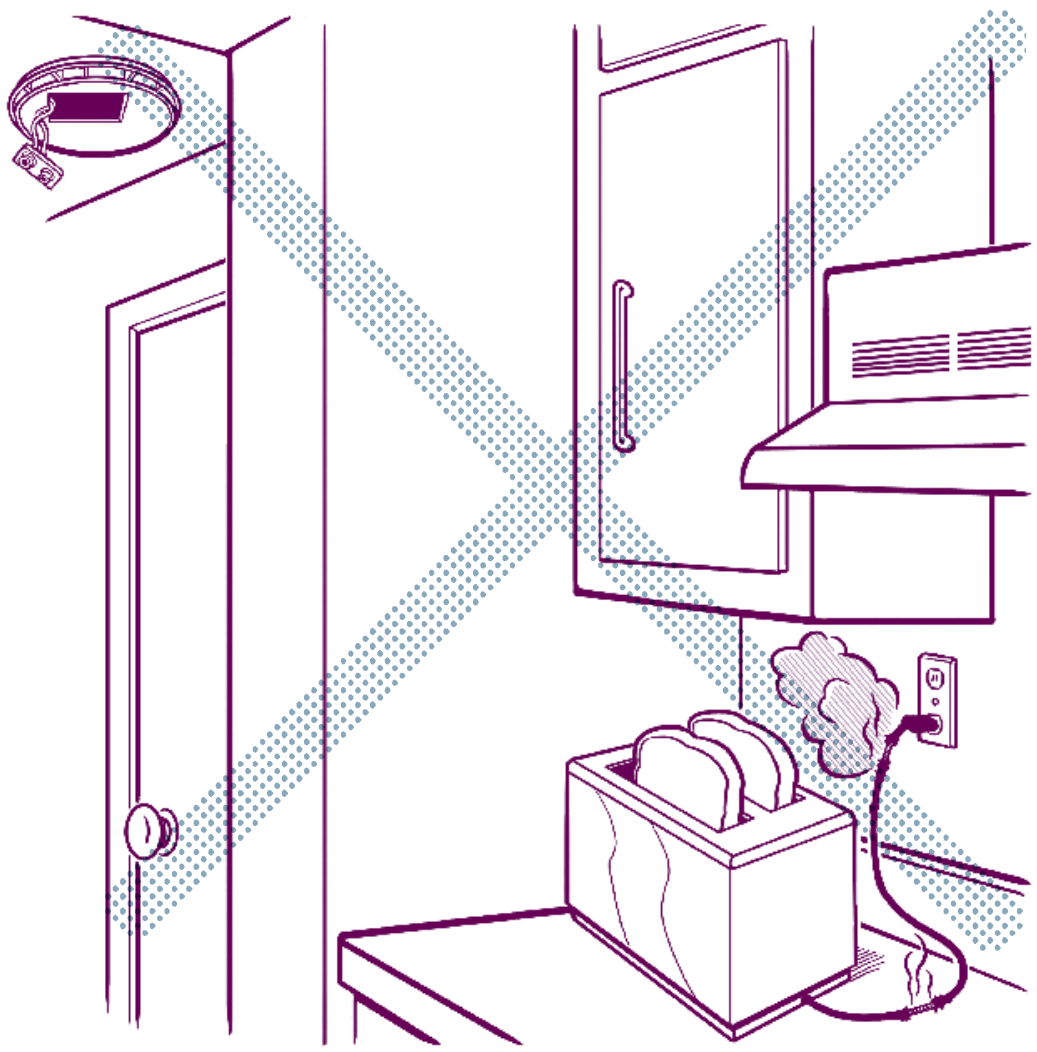

! watch out for

Electric shocks • Burns 


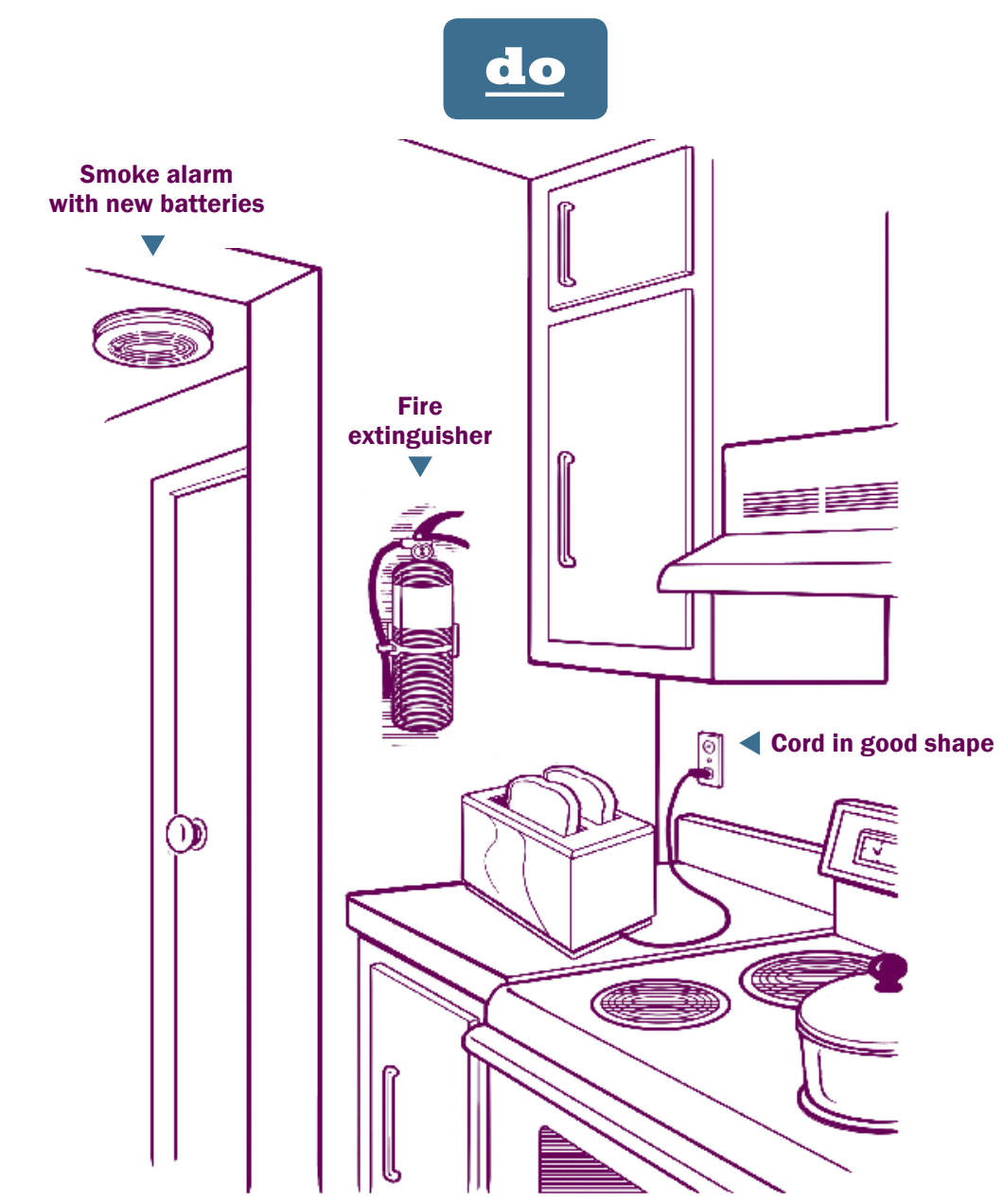

\section{tools}

Have these things available or installed to make the job safer:

- Smoke alarms on each floor (Check batteries at least once a year.)

- Fire extinguisher-Know where it is and make sure it has been serviced regularly. Get training on how to use it. If there is no extinguisher, ask the client or apartment manager about it, if appropriate. 
"We live in San Francisco, where there are earthquakes! It's important we plan together in case we have to evacuate. I've made sure we both have emergency contact numbers in case anything should happen."

Patricia, client

\section{tips}

\section{General fire safety:}

- Plan and practice evacuation in case of a fire. Know where the exits (including windows) are.

- Write down emergency numbers, and in case of emergency dial 911 to reach the fire department, police, or emergency medical services.

- Don't use water to put out a cooking fire. Use an extinguisher, or smother the fire instead.

- Make sure the stove is turned off when not in use.

\section{- Place space heaters away from pathways} so they won't be knocked down. Keep them away from fabric, clothing, and items that can burn.

- Remove lint from the dryer before doing another load. It could catch fire. 


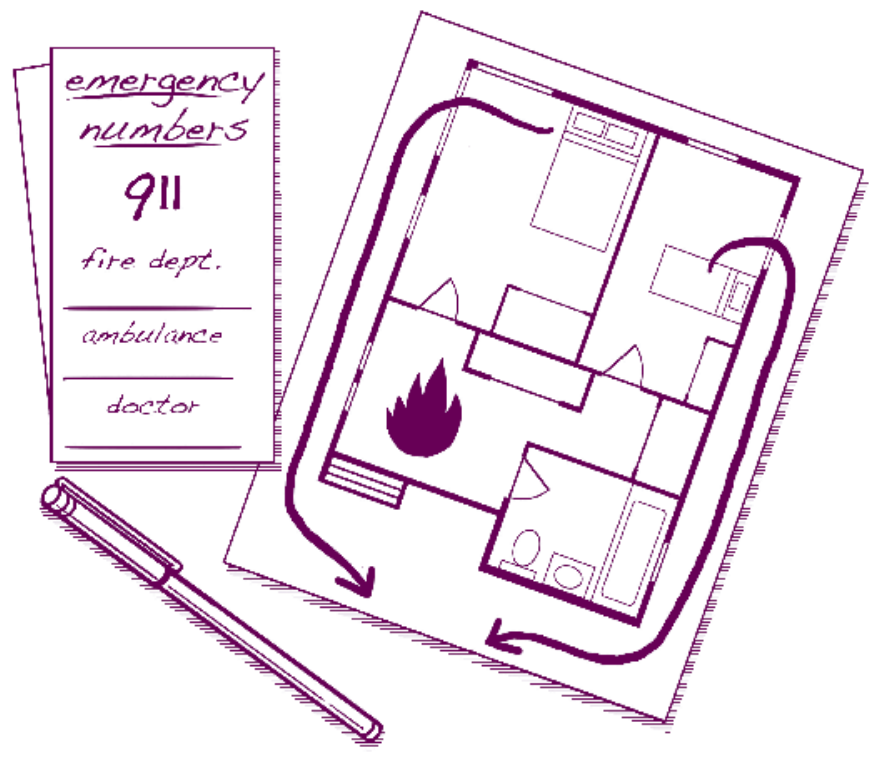

Cigarette smoking is the most frequent cause of fires in the home.

- Make sure lit cigarettes are never near flammable items such as oxygen tanks, paper, drapes.

- If the client smokes and takes medication that causes drowsiness or forgetfulness, pay extra attention to prevent a fire.

- Put water on cigarettes before throwing them in the trash.

- Advise the client not to smoke in bed. Make sure that ashtrays are located away from mattresses and bedding. 


\section{Oxygen}

- Keep all flames away from oxygen equipment. Flame sources include lit cigarettes, candles, matches, stoves.

- Store oxygen tanks in well-ventilated areas.

Do not put them in closets or other small spaces.

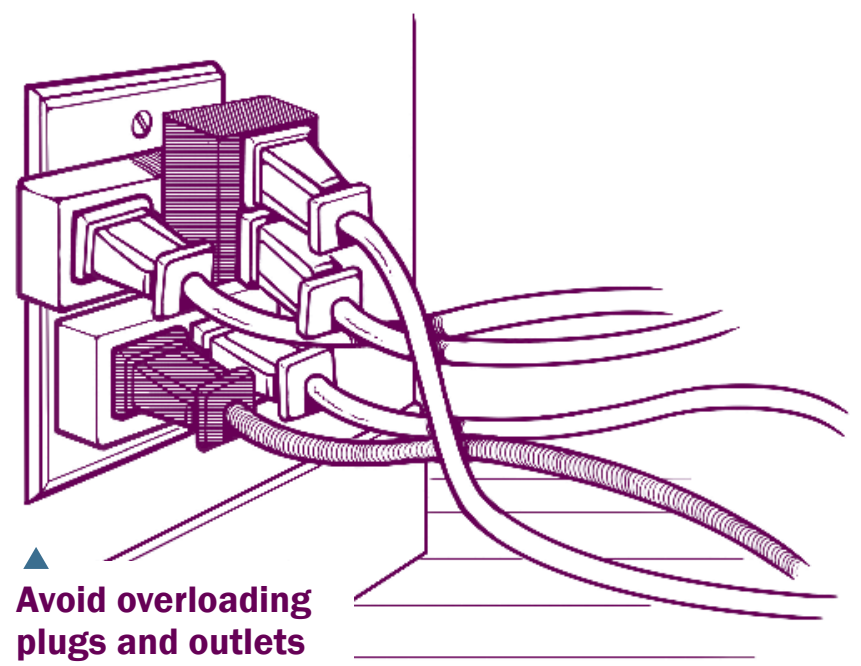

\section{Electrical safety}

- Avoid putting too much of a load on extension cords. (Check the rating tag on the cord.)

- Have missing outlet covers and frayed cords replaced.

- Check that appliances like lamps, hair dryers, coffee makers, mixers, microwaves, and toaster ovens are in good condition with intact cords and plugs. 


\section{Electrical safety continued}

- If you get even a small shock from an appliance, stop using it immediately until it's fixed.

- Never use a hair dryer, radio, TV, or other electric appliance near water.

- A light switch or electric outlet hot to the touch can indicate unsafe wiring-get help!

- Do not place electrical cords under rugs or carpets.

\section{talk it over}

You could say this: "Smoke alarms and fire extinguishers will make your home safer and help protect us both. What can I do to help you get them?" 


\section{find help}

- Many hardware, home supply, or general merchandise stores carry smoke alarms and $\mathrm{CO}$ detectors. Call your local fire department (on a nonemergency telephone number) for suggestions. Some fire departments may also provide seniors and low-income individuals with smoke detectors and help install them.

- If the client lives in an apartment building or senior residence, get permission from the client to ask the building manager for a smoke alarm.

- Most local hardware stores sell fire extinguishers. Get an all-purpose type (called ABC dry chemical $10 \mathrm{lb}$. extinguisher).

"I sit down with the client at the first visit and we go through numbers to call, including doctors and family, and how to get out in case of fire or other emergency."

Jackie, homecare worker 


\section{to do list}

Supplies needed:

$\square$ Smoke alarms $\quad \square$ Fire extinguisher

$\square$ Other:

New ways to do the tasks:

People or places we will contact for help, tools, or information: 


\section{Dealing with stress from the job}

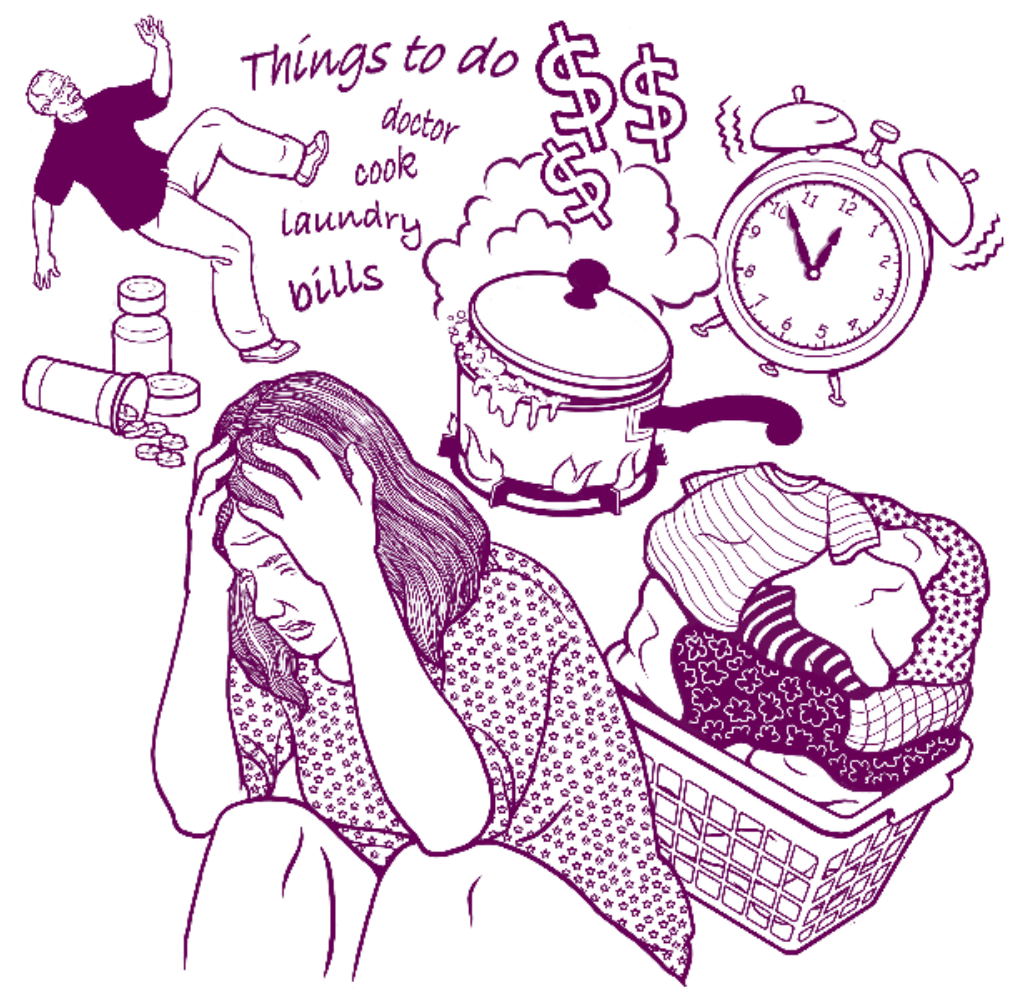

watch out for

Stress happens when your mind and body are overloaded with pressure and worry. This overload is not good for your health, especially if it continues for a long time. 


\section{Causes of job stress for homecare workers include}

- Concern about the well-being of the client.

- Long hours.

- Pressure to do tasks quickly or too many tasks at once.

- Fears about losing your job.

- Poor communication between you and the client.

- Job tasks that you believe are hazardous or conditions in the client's home that you believe are unsafe.

- Requests to do tasks that are not part of your job.

\section{Too much stress on the job can make you}

- Feel sad and depressed.

- Cry more often than usual.

- Have low energy.

- Not want to do things you used to enjoy.

- Have sleeping problems.

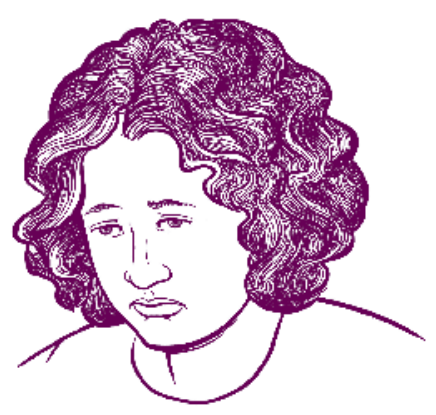

- Have changes in your appetite.

- Become sick more often.

- Increase use of alcohol, tobacco, or drugs.

- Feel angry at the client or other people.

- Think about hurting yourself or others. 


\section{tips}

- It's hard work caring for another person. Take care of yourself! If you don't, you won't be much help to anyone else. Here are some ways to deal with stress on the job:

- Make a list of what is causing your stress at work. Are there ways to reduce these problems?

- Start by selecting one or two issues to work on so you don't feel overwhelmed.

- Talk to friends, family members, or other homecare workers.

- Call an agency or program for help. (See find help section, on page 68.)

- If appropriate, talk to the client about the problems. You might invite a person who is supportive of you and the client to be present. Come prepared with ideas for possible solutions. 
- While you're trying to work out problems on the job, follow some healthy-living suggestions:

- Exercising.

- Eating well.

- Talking to a friend or counselor.

- Getting enough sleep.

- Keeping up-to-date on vaccines, such as flu shots.

- Trying to avoid alcohol and drugs.

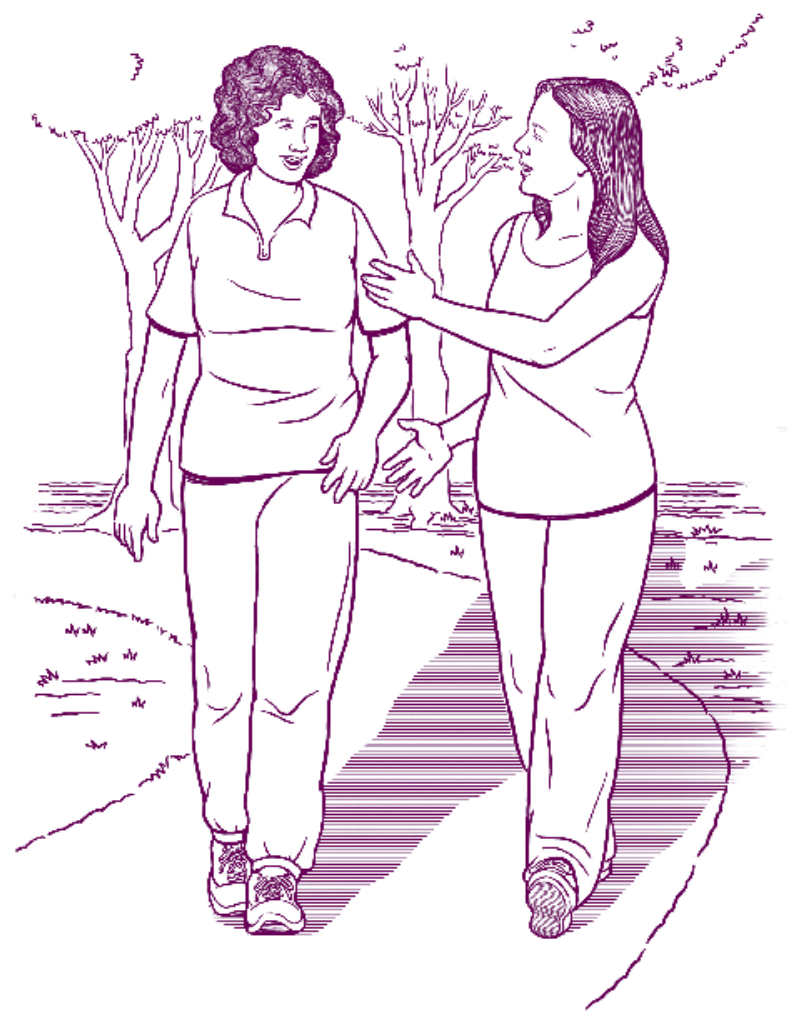




\section{? find help}

- Problems Getting Paid by Employer

If you work for an agency or company, call your employer. Your union can help you with this, too.

If the problem is not resolved, contact the Wage and Hour Division of the Department of Labor in your state. To find the local office in your state, look online at www.dol.gov/whd. You may also look in the front of your phone book for state government pages. Find the state department of labor. The wage and hour division will be listed there. (You can also call 411.)

\section{- Harassment}

If you are being harassed or discriminated against by your client or someone else living in the home, report it to your agency or company. If you are in a union, ask your union to help you with this, too.

\section{- Elder Abuse}

If there is abuse in the home, or if someone is abusing the client, contact Adult Protective Services in your state. Look in front of your phone book in the State Government section. (You can also call 411.)

\section{- Counseling Help}

To find out about counseling services contact your medical provider, employer, or a community or religious organization. 
New ways to handle stress:

People or places we will contact for help, tools, or information: 


\section{What to do if you are hurt on the job.}

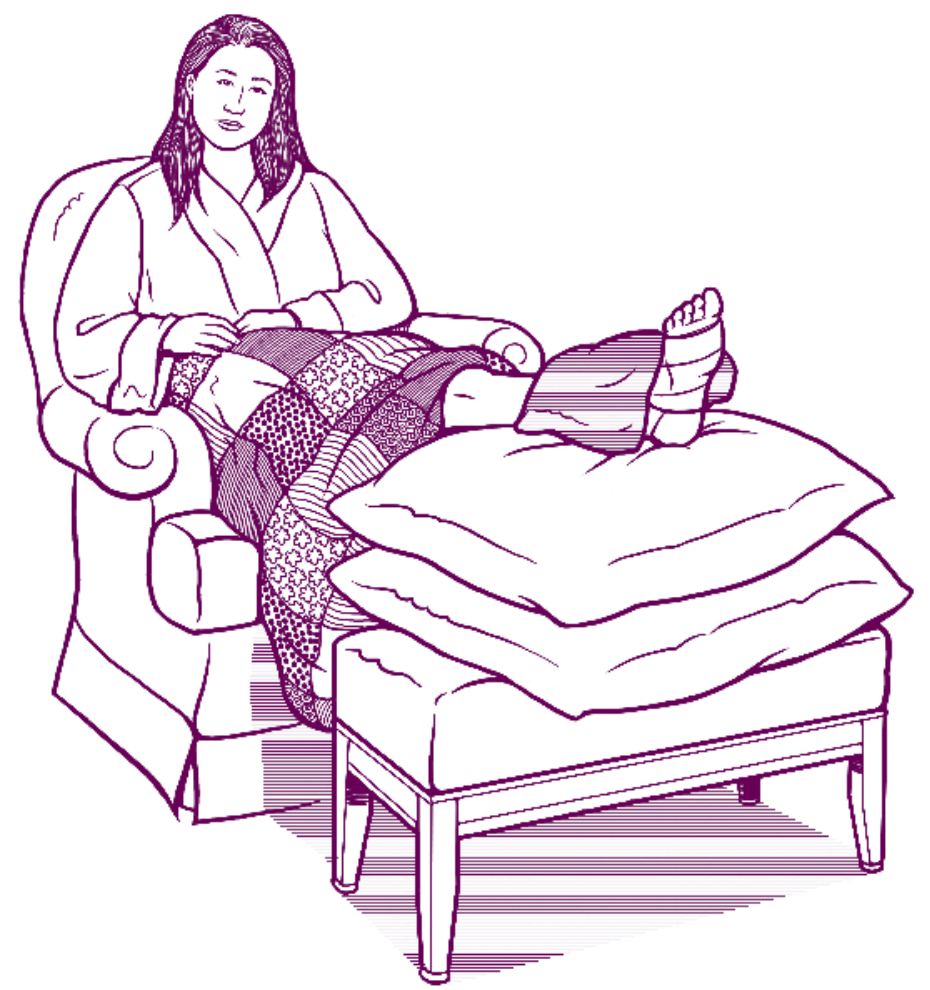

How do work-related injuries occur?

- Through a single event, such as falling and hurting your back or getting burned while cooking for the client.

- Through repeated activity or contact, such as back strain from daily assisting with transfers; asthma from repeated exposure to animals, dust, or cleaning products; or a skin rash from using chemicals or repeatedly washing hands. 


\section{tips}

\section{What to do if you get hurt on the job}

- Get medical treatment. If it's a medical emergency, call 911 or go to an emergency room right away! Make sure to tell the doctor that your injury happened at work.

- Report the injury promptly to your client and your employer, if you work for an agency or company.

- Talk to your client or agency to figure out how you can make your workplace safe to prevent future illnesses or injuries.

\section{? find help}

Find out if you're eligible for workers'

compensation that can cover medical care and some lost work time.

Ask your employer for information about the benefits you may be entitled to.

- Contact your union, if you have one. Your union might also be able to provide information about any benefits you might be entitled to.

- You can contact the Workers' Compensation office in your state. Look in the front of your phone book for State Government pages. Look for a listing for Workers' Compensation. If you can't find it, try calling 411. 


\section{Our action plan for safety}

(D) Make a plan to help you and the client stay safe together. Look back at each safety tip and make a list.

Supplies you need:

Safety tips you will follow:

Issues you need to discuss:

Phone numbers to call, organizations to contact for help: 


\section{Our action plan for safety}

Make a plan to help you and the client stay safe together. Look back at each safety tip and make a list.

Supplies you need:

Safety tips you will follow:

Issues you need to discuss:

Phone numbers to call, organizations to contact for help: 


\section{Our action plan for safety}

Malke a plan to help you and the client stay safe together. Look back at each safety tip and make a list.

Supplies you need:

Safety tips you will follow:

Issues you need to discuss:

Phone numbers to call, organizations to contact for help: 


\section{Our action plan for safety}

Malke a plan to help you and the client stay safe together. Look back at each safety tip and make a list.

Supplies you need:

Safety tips you will follow:

Issues you need to discuss:

Phone numbers to call, organizations to contact for help: 


\section{Our action plan for safety}

Malke a plan to help you and the client stay safe together. Look back at each safety tip and make a list.

Supplies you need:

Safety tips you will follow:

Issues you need to discuss:

Phone numbers to call, organizations to contact for help: 


\section{Acknowledgements}

This handbook was developed by staff from the following organizations:

Labor Occupational Health Program (LOHP) at UC Berkeley, www.lohp.org.

The National Institute for Occupational Safety and Health (NIOSH), www.cdc.gov/niosh/.

The Public Authority for In-Home Supportive Services (PA for IHSS) in Alameda County, www.ac-pa4ihss.org.

The Service Employees International Union-United Long Term Care Workers (SEIU-ULTCW), www.seiu-ultcw.org.

Underground Advertising (original handbook design).

Mary Ann Zapalac (original handbook illustration).

Special thanks to the following homecare workers and clients who contributed to the initial development of this handbook, including:

Workers: Thanh Ahlfenger, Teresa Armas, Brenda Blannon, LiYa Chen, Maria Luisa Figueroa, Faye Herald, Xin Fang Huang, Phyllis Malandra, KeTian Ouyang

Clients: Mark Beckwith, Rosa Ortiz, Carmen Rivera-Hendrickson, Michelle Rousey

We also thank the many people, agencies, and organizations in the community who participated in developing the original as well as this nationwide version of the handbook. 


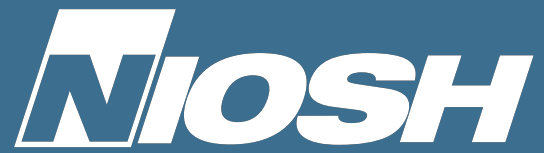

Delivering on the nation's promise: safety and health at work for all people through research and prevention.

To receive NIOSH documents or more information about occupational safety and health topics, contact NIOSH:

1-800-CDG-INFO (1-800-232-4636)

TTY: 1-888-232-6348

CDC INFO: www.cdc.gov/info

or visit the NIOSH website at http://www.cdc.gov/niosh.

For a monthly update on news at NIOSH, subscribe to NIOSH eNews by visiting www.cdc.gov/niosh/eNews.

DHHS (NIOSH) Publication No. 2015-103

SAFER • HEALTHIER • PEOPLE ${ }^{\mathrm{TM}}$ 